\section{UCDNN}

LIBRARY
University of Connecticut OpenCommons@UConn

June 1975

\title{
Computerized Interactive Orthodontic Treatment Planning
}

Richard D. Faber

Follow this and additional works at: https://opencommons.uconn.edu/sodm_masters

\section{Recommended Citation}

Faber, Richard D., "Computerized Interactive Orthodontic Treatment Planning" (1975). SoDM Masters Theses. 35. https://opencommons.uconn.edu/sodm_masters/35 


\title{
COMPUTERIZED INTERACTIVE \\ ORTHODONTIC TREATMENT PLANNING
}

RICHARD D. FABER, B.S.E.E., M.S., D.D.S.

\author{
Submitted in partial fulfillment \\ of the requirements for a \\ cartificate in Orthodontics \\ April 30, 1975
}

DEPARTMENT OF ORTHODONTICS
SCHOOL OF DENTAL MEDICINE
UNIVERSITY OF CONNECTICUT
FARMINGTON, CONNECTICUT 06032

This paper is not to be copied or duplicated either in part or in its entirety without the author's permission.

UNIV. OF CONN.

NOV 291976

HEALTH CENTER LIBRARY 


\section{TABLE OF CONTENTS}

Page

I. Computerized Interactive Orthodontic Treatment Planning

A. Introduction

B. Review of the Literature 3

C. The Computer and its Application 6

D. The Treatment Planning Program 8

E. Summary and Conclusions 12

II. Technical Program Description

A. Introduction 14

B. CEPH 1215

C. CEPH 2

D. $\mathrm{CEPH} 3 \quad 24$

E. CEPH $4 \quad 28$

IV. Instructions for Program Use 29

V. Tables and Figures 34

VI. Bibliography $\quad 35$

VII. Acknowledgements 
COMPUTERIZED INTERACTIVE TREATMENT PLANNING 


\section{COMPUTERIZED INTERACTIVE ORTHODONTIC TREATMENT PLANNING}

INTRODUCTION

Computers and computer programs for digital computers are presently being utilized in orthodontics for cephalometric analysis and for data retrieval systems. Cephalometric analysis using a computer program is a relatively well defined problem. The skeletal landmarks are converted into coordinates in a geometric space and an analysis chosen. A computer program can then be written to calculate the desired angles and distances. If standards are available for the analysis then the results can be compared to the table of standards that are already stored in the computer. Intervention by the clinician is not required once the cocrdinate points are selected and the data are entered into the program. This process results in time saving to the busy clinician. The data retrieval systems that are presently in use are located in major teaching centers and are used for rapid access to large banks of growth data. Record systems also fall into the retrieval system area and some of these are presently available as a service to the orthodontic clinician in practice via various entry modes.

Computerized patient diagnosis has long been worked at in medicine and is beginning to take strides in orthodontics. Computerized programs for diagnosis go a step beyond a data retrieval system since they require the definition of meaningful criteria to establish conclusions about the stored data base. The treatment planning of an orthodontic patient must be preceded by three distinct steps: 
1) records such as models, headfilms, etc. are obtained, 2) data is collected from these records and directly from the patient and 3) data and/or secondarialy derived data are compared to standards to establish a differential diagnosis for the patient. The computer program performs well in the storing of vast amounts of data and organizing them rapidly into predetermined categories. The drawing of conclusions for a differential diagnosis and treatment planning is a more sophisticated problem. At the present state of the art there has been only limited success in achieving these goals. It is fair to state that although the computer program can greatly aid in amassing and organizing the diagnostic data base information it is still the clinician that must assimilate and soundly interpret the results.

The field of computerized orthodontic treatment planning is at present one of the "vogue" areas. This step is unfortunately a quantum jump both for computer programs and orthodontic clinicians at the present state of the art. The treatment planning process although conceptually defined by many is not defined to the detailed level required to allow a "machine" (computer program) make all the key decisions. The complexity of the problem becomes apparent when we begin to look at the multifactorial subjective variables of clinical judgment, such as, facial esthetics, biology, stability, growth, and the weighting of the importance of treatment objectives.

The problem of computerized treatment planning itself suggests that an interactive approach should be undertaken. Cybernetic science suggests that in cases of undefined functions in feedback loops that operator intervention is a solution. 15 This allows the computer program to do the routine readily definable tasks and yet allows the orthodontic clinician to make the key decisions for each step in estab- 
lishing a logical treatment pian for the patient. This approach realistically utilizes the optimum performance of both the computer and clinician to a maximum. The term "interactive system" implies that a trained orthodontic clinician is an active figure in the feedback loop for each major treatment decision (See Fig. 1). A graphic display terminal is used to allow the orthodontist to visualize the treatment changes that are being planned for the patient. The configured system is a real-time system simulation since the clinician is actively conversing with the computer program during its execution.

It is an important philosophical point that the orthodontic clinician be included in the program steps. This approach is unique in orthodontics although for many years it has been used in engineering system design in both areas of industrial and scientific application for problems with undefined variables and functions.

The purpose of this research endeavor is to develop an integrated simulation system with the capability of doing orthodontic treatment planning utilizing a computerized interactive graphics system. The system has been developed to include the orthodontic clinician for making key treatment planning decisions and utilizing the computer program to perform the routine tasks and calculations.

\section{REVIEW OF THE LITERATURE}

The literature related to the uses of digital computers in dental science is relatively small. A survey by the author of the present uses of computers in dentistry showed that the applications fall into four major categories: data storage and retrieval systems, analytic systems, simulations, and real-time systems. The above order is also the list of most uses to least uses. 
There is almost no mention in the literature of the use of computer systems for interactive simulation programming to aid the researcher or clinician in orthodontic treatment planning for the patient. The major thrust of the computer applications to orthodontics has been in an area that is loosely termed "computerized cephalometrics." This category of applications involves two areas. The first is the study of growth and development, and growth prediction of the facial skeleton on both a longitudinal and a cross sectional basis to see if growth trends and patterns can be established. The second is the cephalometric anaiysis of patients who are to be treated orthodontically and comparing their measurements to available standards. The latter use has gained some prominence with its availability as a commercial service to practicing dentists and orthodontists. ${ }^{2}$ Although the dental literature contains no direct references to interactive uses of computers in treatment planning, some of the reported work on simulations and analysis does help to support the basic concepts that are utilized in this project.

The use of computer programs developed to do cephalometric measurements has been reported by several investigators. 3,4,5,6 A lateral head plate tracing is converted into $X-Y$ coordinate points either by hand or by an electronic digitizer. A digitizer is a device that converts $X-Y$ coordinate points on a graph to electronic signals that signify the numerical coordinate locations of these points in a geometric space:" This is usually done by placing a pointing device at the rocation to be converted and transmitting this location to an electronic device that converts the physical location to an electrical analog and thus to an $X-Y$ coordinate. This data is then fed into a digital computer. Once the data is stored in the computer in its $X-Y$ coordinate form any number of mathematical manipulations can be performed to measure the angles and distances between sets of points. If a data bank of standards is available,,$^{7,8,9}$ then the measured data can be compared 
to the standards and relative to the standard "diagnostic" information is obtained. The concept of digitized information has been used in the study of dental arch form. 10,11 The arch form is digitized by inputting the cusp tip $X-Y$ coordinate positions and measurements of arch form and arch width are done automatically by a computer program. In the case of simulation 11 if a curve for the arch form has been predetermined then teeth can be moved along the curve and arch length or available space can be determined. The drawback to this type of simulation is that the mathematical general curve shape for the arch form that is fitted to the $X-Y$ coordinates is either parabolic ${ }^{11}$ or a trifocal ellipse ${ }^{12}$ which is an approximation to the arch form. To date no major study has shown that the arch form for the human dentition actually approaches a mathematically defined curve in its entirety.

An in depth review of the literature revealed that no satisfactory model has been developed that includes as components the facial skeleton, dentition and soft tissues drape of the face. However, models for the individual component parts, i.e., lateral sku11, soft tissue, arch form, frontal skuli have been reported on in the literature. $10,11,12,13$

The study of growth and growth prediction using the digital computer has been limited. The major thrust has been on skeletal patterns of lateral head films. $9,13,14$ These studies generally look at the changes of the lateral facial skeleton with age to get at the problem of growth prediction. 16,17

In general, it can be stated that the use of computers to analyze orthodontic data base information is in a formative stage of development. The application of computers and graphic displays for orthodontic treatment planning is at present unreported in the literature although this approach has been suggested by Walker. 
THE COMPUTER AND ITS APPLICATION

The word "computer" has come to mean many different things to different people. Before embarking on a discussion of computer system synthesis it is important to understand the basic terminology. Digital computer systems are usually composed of two parts, the hardware and the software to use common jargon. The hardware is the fixed unchangeable component of the system. It is usually composed of the electronic equipment. The software component of the system is the program that is written to perform the various tasks involyed in the solution of a particular problem. The software is changeable to meet the particular needs of a user.

The hardware system that has been synthesized to meet the specialized problem needs of the interactive orthodontic treatment planning system is dipicted in Fig. 2 and the photographs of Fig. 3. The heart of the system is a Computer Automation A1pha-16 mini computer with 24k of memory. The computer acts as the central processor for the perifera? equipment that interfaces with it including the orthodontist. The major communication device used by the operator is a Tektronix 4010-1 graphic display terminal and keyboard. It is via this terminal that the operator commands the system program operation, interfaces with the treatment planning program, and is able to view the graphic simulation that is provided. The digitized data is entered into the system via a Summagraphics magnetic tablet digitizer. The digitizer converts the $x-y$ cartesian coordinates to electronic data signals and inputs the data directly into the computer. This is done by touching the pen sensing device to the desired location on the digitizer tablet as shown in Fig. 4. A Complot Digital Plotter is used to obtain final hardcopy tracings of the treatment plan actual size $(1: 1)$. Copies of the graphic terminal display can be obtained by utilizing the Tektronix 4610 copy unit. These 
copies are approximately three quarter scale (1:0.75). The data and programs are stored on a Diablo series 40 disk drive with a storage capacity of 50,000k bits. The disk file system is directly addressable for programs and data. Additional storage is provided by a Ross dual drive cassette system. The entire system is capable of communication via telephone modems to large data banks that are stored on the University of Connecticut Univac 1106 computer system. The system is also capable of operation by remote operators via a modem telephone system.

The software that has been utilized in the system can actually be divided into two parts, the executive software and the treatment planning software. Since it is not the purpose of this paper to discuss the specific technical details of the executive software, suffice it to say that the program is written in the BASIC computer language and that TEK-10 the Tektronix graphical program was used in part along with some system executive software that was supplied by manufacturer of the computer.

The treatment planning software for the interactive system is outlined in Fig. 5, which is an overall flow chart of the major program steps. The details of each step will be described in the discussion section with an example of a case. The present study limits itself to treatment planning on a lateral headplate to obtain an astimate of lower incisor position. The lateral skul] and soft tissue model that has been developed to do this is illustrated in Fig. 6 . It consists of 47 points that are entered as digitized data for the graphics program. The model has been developed to get a minimum number of points, yet be useful and meaningful clinically. The Frankfort Horizontal is a fixed plane that is offset from the $\mathrm{S}-\mathrm{N}$ line by seven degrees. The human engineering aspects of the program have been designed to make operation as simple as possible. 


\section{THE TREATMENT PLANNING PROGRAM}

Prior to going into a detailed description of the treatment planning program it is important to set some philosophical ground rules. It is not the purpose of this paper to substantiate or disprove any given assumptions used for treatment planning, but rather to develop a logical systems engineering approach which is applicable to treatment planning the specific needs of the individual patient. The mathematics and geometry of the situation can only describe the size, position, and angular relationships of the parts in space. This can be done with a computer program, but the final judgment and integration of the data still cannot be defined to the discrete levels required by the program and thus these decisions have been left for the trained orthodontic clinician to make. The program is designed to work with the clinician. It organizes and presents the primary data base information in a meaningful form. 'It calculates and organizes secondary or derived data base information. It alerts the operator to the important criteria for each decision and computes updates of the required measurements. The program then displays and simulates what the operator desires on the graphic display and recomputes the affect of the change on the relevant measurements.

It is fundamental to understand that the computer and its program is an AID to the orthodontist and as such that it is only one facet of the complete treatment planning process. The program makes the assumption that prior to formulating a treatment pian the clinician has collected a complete data base (records, models, $x$-ray films, clinical examination) on the patient and formulated a list of the patient's problems requiring treatment.

The treatment planning software has been written with modularized packages for each major step so that as basic research in various areas becomes available 
that is pertinent to a particular step, it may be included in the program updates with relative ease. The program sub steps themselves also function as separate software modules.

The remainder of this discussion will attempt to illustrate via an example of a patient with a Class II division I malocclusion how the program aids the orthodontist in formulating a treatment plan. The Figs. 7 thru 14 are copies of what the operator sees on the Tektronix 4010-1 display terminal.

Prior to beginning the program the orthodontist collects the data base. Utilizing the lateral headfilm tracing he marks the appropriate landmarks as shown in Fig. 6. He then begins the program stream and enters the data with the digitizer pen as shown in Fig. 4. Once the data is entered the operator can correct any of the points he has entered if an error has occurred.

The first step of the program requires the operator to establish a growth prediction for his patient and input incremental growth data. Much controversy has arisen recently about growth prediction. ${ }^{16,17}$ It is not the primary purpose of this program to forecast growth, but rather in steps of the treatment plan where growth factors are relevant variables that some estimate be made. A simple scheme has been chosen to input the growth prediction for a two year period. Using developmental age of the patient, growth increments are selected from tables of longitudinal values and inputted to the program. The increments as noted in Fig. 8 show the three parts of the growth coristruction being used. Cranial base growth is along the S-N line. Midfacial growth as horizontal increments to $A$ point and vertical increments to ANS. The mandibular prediction is along the Y-axis angle to Frankfort Horizontal. The input scheme selected allows any type of growth data to be inputted that the operator desires. 
The second step of the program requires the operator to establish a cant for the treatment plane of occlusion as shown in Fig. 9. This decision is done in two parts. Initially the clinician determines the patient's natural plane of occlusion using data base information. Once this has been done the clinician considers the other factors that might enter into modifying the occlusal plane. These factors are esthetic considerations, periodontal considerations and denture apical base relationships. As illustrated in Fig. 9 the data base along with the standards and measured values are displayed on the screen. As the operator modifies the cant of occlusal plane the new measurements are printed on the display. The simulation moves the occlusal plane as operator indicates so he can see what the change will entail. In the sample case of Fig. 9 the natural plane of occlusion was moved $+7 \mathrm{~mm}$ flatter than the inputted occlusal plane (center rotation is mesio-buccal cusp of the maxillary molar and change measured in $\mathrm{mm}$ at the maxillary incisor). After consideration of the modification factors it was decided to move the plane $+1 \mathrm{~mm}$ flatter than the natural plane as illustrated. Once the treatment occlusal plane has been selected at the end of this step it is used for all the calculation and simulation that follows.

The third step of the program is to establish mandibular rotation. Since the hinging of a mandible open or closed usually requires a growing individual, growth is included in this step. As shown in Fig. 10, the data base is listed for the horizontal and vertical factors for a standard, the original and growth. The tracing on the display shows the original maxillia, the growth maxillia and the growth mandible. In the example of Fig. 10 the mandible is hinged closed two millimeters and the affects of this on the permanent variables are printed out. 
The fourth step of the program is to establish the level of the treatment occlusal plane Fig. 11. This step requires knowledge about the patients growth and the mandibular rotation from the previous step. The data base again keys the clinician to the pertinent information from his data base and the intermaxillary space after rotation and growth is computed. In the sample case (Fig. 11) the levei of the occlusal plane was lowered 1.2 millimeters.

The fifth step of the treatment $\mathrm{plan}$ is to establish the anterior-posterior position of the lower incisor. This decision has been divided into two sub steps. First the ideal profile is determined (Fig. 12) and ther the factors to support that profile are evaluated (Fig. 13). In Fig. 12 the data base for the establishment of a profile is seen. Many of these factors are subjective but are listed for completeress. The profile is selected by inputting upper and lower lip protrusion changes. An $\mathrm{Sn}-\mathrm{Pg}$ line is included for reference. In the example the upper lip was retracted $2 \mathrm{~mm}$ and the lower lip was protruded $3 \mathrm{~mm}$. Once the profile is chosen then inputs for the tissue drape thickness of the upper and lower lip can be updated. The second part of step five is illustrated in Fig. 13. The data base includes a table of tissue thickness, standards and the considerations for perioral function and stability. The program does a position estimate of lower incisor based on cissue drape, thickness and overbite to support the desired profile. The simulation then draws the new positions. At this point the operator is given the option of overriding the selected position on the basis of the presented information.

The sixth step of the treatment plan is shown in Fig. 14. This table is a summary of the treatment changes that the orthodontist has selected for the patient. 
SUMMARY AND CONCLUSIONS

This research shows the development of a computerized interactive graphics system for organizing data base information and doing orthodontic treatment planning. Since other investigators have looked at the requirements of an orthodontic data base and the problem of diagnosis it was felt that the problem of treatment planning would be a challenge. The system was developed with the philosophy that the computer could be an aid to the orthodontist in organizing and displaying the information required for a complete treatment $\mathrm{plan}$ rather than a dictator of treatment as others have proposed. The interactive approach of the orthodontist as a key figure in the feedback decision loop in a real-time computer system for orthodontic treatment planning is a unique feature.

The interactive approach to orthodontic treatment planning has resulted in:

a) A detailed definition of the treatment planning procedures required for implementation on a digital computer.

b) A definition of the interactive steps and the order required to allow a trained orthodontist to obtain a useful treatment plan.

c) A clinically useful two dimensional mathematical model of the lateral skull and soft tissue.

d) A demonstration of the feasibility of an interactive approach to orthodontic treatment planning.

The advantages that are inherent in such a system are:

a) A more thorough data base that is integrated with the treatment plan.

b) A detailed treatment plan that has included a 11 steps for examination.

c) A graphic visualization of the projected treatment changes.

d) A simulation that easily allows changes to be made. 
e) Control of the decisions by the Orthodontic Clinician.

f) Storage and retrieval of data as it is required for each step.

g) A time savings to the busy clinician since when he sits down to do the treatment plan the data is presented in a orderly and organized fashion.

It may not be to far in the future that the cost and technical advances in computer terminal technology will put a computer terminal or computer system in the realm of the private practioners office. Certainly the costs have come down considerably in the past several years and will continue to do so as the useage rate increases. This will certainly increase both the demand and feasibility of such a system. 
TECHNICAL PROGRAM DESCRIPTION 


\section{TECHNICAL PROGRAM DESCRIPTION}

\section{INTRODUCTION}

The computer program for orthodontic treatment planning is constructed with both macro and micro program modules. This approach facilitates program usage on the Alpha-16 Computer System. The program is composed of four macro packages called CEPH 1, CEPH 2, CEPH 3, and CEPH 4. Each of these macro programs is directly addressable via the disk file manager. The chart of Fig. 15 shows the functional pieces contained in the macro program modules. Each of the macro programs has a basic core module called CEPHTEK. The CEPHTEK Program contains ALPHA-16 BASIC, Tektronix TEK-10A and the software linkages for the periferal equipment associated with the system.

The micro programs in the macro units have been written so that they share common micro modules to perform both the common and specific tasks of any one macro unit. Table II 1 ists all the micro program GOSUBS that are utilized with their purpose and where they are used. In the majority of cases common statement numbers for the micro programs have been used between macro programs to avoid confusion. Table I lists all the variables with a description of their functional definitions. Table III lists the CALL statements that are used to interface the programs and the data with the disk file manager.

An overview of the macro programming segmentation is shown in Fig. 15. along with the functional packages that are included within each section. Program flow charts for each macro module are shown in Figs. 16, 17, 18 and 19. These flow charts give the sequencing of the steps within any program module. The micro program units are discussed in the macro program descriptions. 


\section{CEPH 1}

The functions of the CEPH 1 Program macro module are listed under CEPH 1 in Fig. 15. The flow chart of this program section is shown in Fig. 16. The first part of the program initializes the system. The initialization consists of initializing the TEK-10A graphics package that is used in the vector display and setting the variable table equal to zeros. This is performed by utilizing GOSUB 9000 and GOSUB 8802 . Once the initialization is complete the program is ready to accept data and begin the run stream.

Prior to discussing the next step it is important to comment on the variabies used in the program for the storage of the digital coordinate point data. This data is stored in the double subscripted variables $X(J, I)$ and $Y(J, I)$ which represent two three dimensional matrices. The I index is used to reference the points that are used in the anatomic skull model, the range being 1 to 47 . The I index has been constructed so that continguous subsets of points represent distinct anatomic parts of the model. This has been done for ease of handling of the graphics pachage and to make the digitizing stream coherent. The $J$ index is utitized to tag the type of data to be manipulated by the program. The $J=0$ index is used to store the original headplate data once it has been scaled and unit corrected. The original data matrix $(J=0)$ is not altered throughout the program once this function has been completed. The $\mathrm{J}=0$ data is available to the program and can be called at any time it is required. The $\mathrm{J}=1$. index is used to store the updated growth estimate data. This data matrix is essentially fixed once the growth 
prediction part of the program has been executed. Like the matrix of original data it can be recalled at any time the program requires it. The $\mathrm{J}=2$ index is the data matrix in which a 11 of the treatment planning decisions are stored as final coordinates change. The data in this matrix is heterogenous in nature and utilizes both $t$ he original and growth data coordinates as they are required in each program step. Once a treatment plan decision has been finalized the $\mathrm{J}=2$ matrix for that segment reflects the final decision and it is that data which is stored. Utilizing the $\mathrm{J}$ and $\mathrm{I}$ index format allows the jrogram to utilize common mathematical and graphics micro program packages for almost all of the functions required in the treatment planning program.

The input of the digitized data via the Summagraphics digitizer requires some preparation by the operator. Prior to digitizing, a tracing of the lateral headplate is made and the points to be digitized are marked along with the construction of a Frankfort Horizontal line offset seven degrees from the S-N line. The tracing is oriented on the digitizer tablet so that the F-H line is oriented along the X-Axis. The operator then begins to digitize the data. The graphic display for the input routine is shown in Fig. 7. The program is constructed so that after the entry of each point an audible beep is heard indicating to the operator that the program has accepted the data point. The program input routine for the digitized data is called by GOSUB 5002. Once all the data ( $47 X, Y$ coordinates) have been entered into the data file the program calls GOSUB 4900 which is an error correction micro program for altering any coordinate points that may have been incorrectly digitized. This routine is designed so the operator inputs the I that is to be updated 
and then simply redigitizes the point. The next micro program executed is GOSUB 5033. This micro program performs three functions. First, the $X, Y$ coordinate point units are converted from inches to millimeters. This must be done since the digitizer electronics are set up in the English system and record the coordinates in inches. The second thing done is the tracing coord inates are offset to adjust the tracing to the proper centering on the Tektronix 4010-1 graphics display terminal screen. The third step sets the value of $K$ which adjusts the lower border margin of the display screen.

The CEPH 1 Program then proceeds to establish the growth prediction. This is initiated by calling the micro program GOSUB 6504. The growth prediction as configured in the program is based on a two year estimate. The data that is utilized as input is the incremental data available from the Denver Longitudinal Growth Study Tables. The operator data. input routine is simple in that it requests the increments that are to be selected from the tables be inputted via the Tektronix 4010 Keyboard. The growth prediction input display is shown in Fig. 8. The program sums the increments as they are inputted into the program. The calculation of the growth prediction requires that the original data $(J=0)$ coordinates be upciated to the growth data $(J=1)$ coordinates. The coordinate system used for. $X$ and $Y$ sets the $X$ Axis parallel to the Frankfort Horizontal Line. The calculations for the growth prediction are shown in Figs. 20A, 20B and 20C. The S-N growth prediction as shown in Fig. 20A uses $X$ and $Y$ increments that are derived from the total increment along the S-N 1 ine. The equations are listed. The S-N prediction change is used to update the $\mathrm{S}-\mathrm{N}$ line 
and the soft tissue profile points 30 and 31 . The mid-facial growth prediction is shown in Fig. 20B. The increments in the reference table that are used are given as perpendicular and parallel to the Frankfort Horizontal measurements so the update equations are straight forward as shown in Fig. 20B. The mid-facial growth estimate updates the maxilla and associated structures plus the soft tissue points 32 to 38. The mandibular growth prediction is shown in Fig. 20C. The input to this prediction requires that the $Y$ Axis angle be inputted in addition to the $Y$ Axis length incremental change. As the equations in Fig. $20 \mathrm{C}$ show this angle is used to update the coordinates. The skeletal update is performed on points 5 through 18 and soft tissue update is done on points 39 to 44 . It should be noted that in each growth estimate for soft tissue that the skeletal change has been used. This simplistic approach was used since at this time in the treatment plan program the soft tissue growth forcast is not utilized in direct measurements but only to obtain a graphic representation. All soft tissue treatment planning is done on the original soft tissue drape and profile. The underlying problem is prediction of not only the profile changes but the prediction of the tissue drape thickness changes. The intention is that at a future date the tables of both hard and soft tissue incremental data will be stored on the Disk File and the growth prediction can be automated so only developmental age at the start and the number of years for prediction need be inputted into the program. At that time the micro program GOSUB 6504 need only be replaced with the updated version and the rest of the CEPH 1 macro program remains unaltered. 
The next phase of CEPH I is to establish the cant of the Treatment Occlusal Plane (Fig. 9). This step is divided into two parts. It is initiated with a call to GOSUB 6802. The tracing displayed on the screen is the original lateral headplate. In 2.1 of Fig. 9 the cant of the natural occlusal plane is established and in 2.2 on Fig. 9 the cant of the natural occlusal plane is modified to meet the requirements of a Treatment 0cclusal Plane. The input of the occlusal plane changes is in millimeter change at the anterior part of the plane with the distal end center of rotation at the mesiobuccal cusp of the maxillary first molar. The mathematical package used is shown in Fig. 21. A polar coordinate system conversion is used to perform the rotation function. The range on the input variable $E$ is small enough so that the effectual change in the $X$ direction with rotation can be ignored and the angular change is computed from only the $Y$ direction changes. Again the J, I index system is used so that the routine is generalized for other parts of the program. The Natural Occlusal Plane change is effectuated by GOSUB 6682. The micro program for the polar coordinate rotation is called via GOSUB 6662. Once the operator has selected the natural occlusal plane he is going to use, all the occlusal planes $(J=0,1,2)$ are updated to the selected occlusal plane. This preliminary step has to be done since the inputted occlusal plane will not always coincide with the patient's natural occlusal plane. The next step 2.2 on Fig. 9 is to modify the Natural Occlusal Plane to meet the treatment objectives and to establish a Treatment Occlusal Piane. The step is executed by calling GOSUBS 6816 and 6902. Prior to printing out the criteria for this step 
a secondary data base is computed and the measurements 1isted as part of the displayed text. The calculation for consideration of periodontal attached gingiva is shown in Fig. 22. The ratio can be calculated for either the original $(J=0)$, the growth model $(J=1)$ or the final rotated and translated model $(J=2)$ by appropriately setting the $J$ index. The calculation is called by GOSUB 6842. The calculation for the A-B to occlusal plane measurement is shown in Fig. 23. This micro program module is called via GOSUB 6451 or GOSUB 6453. The mathematical basis of this calculation is that the slope of lines through point $A$ and point $B$ that are perpendicular to the occlusal plane are the negative reciprocals of the slope of the occlusal plane. Knowing this information, the formula for the distance between two parallel 1 ines is derived as indicated in Fig. 23. The micro program package is set up so that by selecting the $\mathrm{J}$ index the proper model is used for the calculation. The use of this micro program allows the calculation of changes as the occlusal plane is manipulated. The standards that are printed in the text are selected from the cephalometric standards for the Denver Growth Study and represent means for male and female data. In step 2.2 on Fig. 9 the operator is presented with the criteria that are used for selection of a Treatment Occlusal Plane (Fig. 9). These factors include the Natural Occlusal Plane that the patient presented, esthetic considerations, periodontal considerations and the effects of occlusal plane cant on apjcal base relationships. As the operator manipulates the occlusal plane the effected change is printed as indicated by NEW $A B(O P)$. The change is given for both the original and the growth models, The growth data is presented so that the clinician can see if growth will enhance the change and to what extent. Upon completion of step 2.2 on Fig. 9 and selection of a Treatment 0cclusal Plane the final data is stored on the disk for transfer 
to the macro program module CEPH 2. Control is then transferred to the disk file manager system (DFM) and the operator calls CEPH 2. 
CEPH 2

The functions for the CEPH 2 Program Macro Module are 1isted under CEPH 2 in Fig. 15. An overall flow chart of this program is shown in Fig. 17. The primary purposes of this program macro module are to establish Mandibular Rotation and the Level of the Occlusal Plane. Once the call CEPH 2 instruction has been executed, the program initializes the data files and the plot routines of TEK 10 as discussed in the CEPH 1 description. The program then reads the data file from the disk that was stored at the end of CEPH 1. The CEPH 2 program then enters the micro program for effectuating mandibular rotation. The derived data base calculations precede the display on the screen. These are initiated by GOSUB 6701. The A-B to occlusal plane is derived as previously described. The ratio for lower facial height is obtained as shown in Fig. 24. The profile angle $\mathrm{N}-\mathrm{A}-\mathrm{Pg}$ is calculated in the micro program module GOSUB 6720. The calculation is shown in Fig. 25. The mathematics used takes advantage of the fact that the slope of each of the lines is known and that the angle between them can be computed as indicated in the final expression in Fig. 25. The display shown in Fig. 10 is the one used in this step. The text is updated with changes for $A B(O P)$, $\mathrm{N}-\mathrm{A}-\mathrm{Pg}$, and ANS-ME/N-ME as each rotational change is executed. The graphic display in Fig. 10 is the Growth $(J=1)$ lateral headplate plus the original maxilla $(J=\varnothing)$. This gives the clinician a visual representation of the intermaxillary growth space. The operator inputs the change as a millimeter measurement from the tip of the mandibular incisor. The new mandibular coordinates are calculated by the micro program routine for the polar 
coordinate rotation as shown in Fig. 21 that has already been described. The new mandible is drawn at this point and the updated measurements printed on the display screen. After this step is complete the $\mathrm{J}=2$ coordinate system mandible is updated to the rotated position selected and the screen is erased.

CEPH 2 then establishes the level of the treatment occlusal plane to be used as is shown in the flow chart of Fig. 17. The data base is again calculated prior to the display's being put on the screen. The calculation for attached gingiva ratio is as previousiy described and shown in Fig. 22. The intermaxillary growth space is computed using the vertical dimension between the mesiobuccal cusp tip of the original $(\mathrm{J}=\emptyset)$ maxillary molar and the mesiobuccal cusp tip of the mandibular molar on the rotated mandible $(\mathrm{J}=2)$. This is done' because the amount of space available is definitely affected by mandibular rotation. The graphic display is shown in Fig. 11 and uses the growth model $(J=1)$, the original maxilla $(J=\emptyset)$, and the rotated mandible $(J=2)$. The visual display allows the clinician to interpret the changes he desires with the relevant data displayed. The mathematics used to move the occlusal plane is shown in Fig. 26. The program micro module is called by GOSUB 1201. The cant of occlusal plane has previously been determined, so all that is left is the level change.

Once the level of occlusal plane step has been completed, the data is then stored on the disk file and control is again returned to the disk file manager system (DFM) as previously described. The operator then calls CEPH 3 to execute the next section of the program. 


\section{CEPH 3}

The functions of the CEPH 3 program macro module are listed under CEPH 3 in Fig. 15. An overall flow chart for this program section is shown in Fig. 18. First the program initializes the system as previously described in the CEPH 2 section. The data is then read from the disk file into the assigned storage area of the program. The first step executed in the program is to estabiish the ideal profile and input any soft tissue thickness updates that may be required in the calculation phase. The profile micro program is executed via GOSUB 1219. The display on the graphics terminal screen is shown in Fig. 12 and is the original $\left(J^{\prime}=\emptyset\right)$ profile. An $S n-P^{\prime}$ line is drawn on the profile for reference. Numerical data is not included in the printed data base at this time, since it is felt that this may inhibit the esthetic decision. It may be that measured data will be added at a later time if user demand necessitates it. The lip protrusion change is operator selected by inputting ( $\$$ ) millimeters of change desired. The graphic display then updates the base profile. The calculation for lip profile update is shown in Fig. 27 and executed by GOSUB 7242. Once the desired profile has been selected, the data is stored in the $\mathrm{J}=2$ update matrix of data. At this point the operator has the option of updating the soft tissue drape thickness measurement if he so desires (5.3 on Fig. 12). The update is operator selectable and if no update is inputted, the calculation as described in Fig. 29 is automatically executed. This step is included so that the clinician can exercise 
his clinical judgment if he thinks there will be variation in the way the program calculates the tissue thickness and the thickness that should be used to arrive at an accurate result. The perfect example where this problem might arise is the patient with a severe lip curl. In this example it may be important to measure the lip thickness at a different orientation than the predetermined calculation. The tissue thickness update micro program routine is executed via GOSUB 7402. Following the tissue thickness update a 1 ip seal coordinate set of points is calculated in GOSUB 7372. This is done because the digitized data is entered from a headplate with the patient's relaxed lip position to allow an accurate tissue thickness representation. If there is no interlabial gap, this computation is ignored. The computation is done on the final lip protrusion profile and is shown in Fig. 28 . In the horizontal plane ( $x$ axis) of space an average is used between the upper and lower lips. In the vertical plane ( $Y$ axis) it is assumed that the lower lip comes up two-thirds of the distance and the upper lip comes down one-third of the distance in closing the interlabial gap. Provision has been made to override this assumption at a later date, but it is not implemented in the present program version.

The next step of CEPH 3 shown in Fig. 18 establishes the anteriorposterior position of the mandibular incisor. The graphic display for this step is shown in Fig. 13. The data base calculations for this step are two-fold. First, the tissue thickness table is computed, and, secondly, based on soft tissue profile and drape thickness, an estimate is made of the lower and upper incisor positions required to support the ideal profile that was established in the previous step. The tissue thickness table is computed in micro program GOSUB 7152 and the calcu- 
lations are noted in Fig. 29. The table is included, since manual changes in lower incisor position by the clinician will require knowledge of this data. The assumption made for the standard used in the data table is that a patient with standard tissue thickness and a three to two, upper lip to lower lip protrusion to the $\mathrm{Sn}-\mathrm{Pg}$ ' line will have the lower incisor positioned on the A-Pg line. However, the estimate of lower incisor position that is printed and displayed on the graphic display is not computed using this method. The calculation used is shown in Fig. 30. The mathematics of this calculation is simple in that it starts with the ideal profile previously selected and computes the incisor position required to support this position. Thus from the new lower lip position the tissue drape thickness plus two millimeters for the upper incisor facial-lingual dimension is subtracted. The lower lip is considered to fall back 1:1 with change in incisor position. The upper incisor is figured on the profile lip position with the upper lip thickness subtracted. A (1:0.6) six-tenths fallback ratio is used on upper lip retraction. Using this calculation scheme in cases with large discrepancies between tissue thickness of upper and lower lip, an overjet will result on the display. In these cases the clinician must make the decision as far as any compromise is concerned. The automatic lower incisor position calculation is executed via micro program GOSUB 7352. Once the data has been calculated the graphic display of Fig. 13 is drawn. The display shows the final ideal profile, the original incisor position, and the newly calculated incisor 
position. The $\mathrm{Sn}-\mathrm{Pg}^{\prime}$ and $\mathrm{A}-\mathrm{Pg}$ lines are included for reference. The clinician has the option to alter the tooth position (5.5 of Fig. 13) if he so desires. Due to present software limitations in BASIC the altered profiles cannot be displayed, only the changed incisor positions. After the lower incisor position is finalized the program stores the data on the disk file and control again returns to the disk file manager (DFM). The next step is to call CEPH 4. 


\section{CEPH 4}

The functions of the CEPH 4 Macro Program Module are listed under CEPH 4 in Fig. 15. An overall flow chart of this program is shown in Fig. 19. The initialization procedure used in CEPH 4 is similar to the ones used in CEPH 2 and CEPH 3. The data is then read into the program from the disk file. Once the data has been read, computations are executed. As previously described GOSUB 6452 (Fig. 23) is used to compute the $A B$ to occlusal plane relationship. GOSUB 6720 (Fig. 25) is used to compute N-A-Pg Angle. GOSUB 7502 is used to calculate the information needed to describe the occlusal plane to the Frankfort Horizontal. This is done by calculating the vertical distance from Nasion to the anterior of the occlusal plane and measuring the angle from occlusal plane to Frankfort Horizontal. The change in level is included for completeness and is computed in GOSUB 7512. The ANS-ME/N-ME ratio is calculated in micro program GOSUB 6841, as previously described (Fig. 24). The printout is organized as shown in Fig. 14. Once the printout has been displayed on the screen it remains until the operator indicates that he is finished with it. At this time control is transferred back to the disk file manager system (DFM).

This completes the description of the detailed program for orthodontic treatment planning. 
INSTRUCTIONS FOR PROGRAM USE 
Instructions for Program Use

The orthodontic treatment planning program is set up to be self instructional once the run stream has been initiated. The preliminary display on the Tektronix 4010 screen describes the commands that are utilized in the program.

It is important that the clinician is prepared prior to starting a treatment plan by having assembled his records, data base and diagnosis. In addition, a tracing must be made of the patient's lateral headplate with the cephalometric land marks shown in Fig. 6 clearly marked. The tracing must be oriented on the digitizer tablet with the Frankfort horizontal line parallel to the $X$ axis. This is done by checking both ends of the F.H line with the digitizer pen until the $X$ coordinates agree within one to two units in the last (right) digit. Once this is done the tracing should be taped down on the tablet.

The hardware configuration must be checked for proper hookup and it is imperative that the PROTECT button on the disk unit be in the OFF position prior to initiating a run. If the operator is unsure of the hardware configuration he should check with the appropriate people prior to starting.

The program is started in the disk file manager system with address 5960 in the program register. The reset, stop, entry, and run buttons are then depressed. The program is initiated by typing E, CEPH 1. When the asterisk $(*)$ returns type RUN and the program will then lead the operator through each decision step. Operator required commands are 
always preceded by $(>, *, ?)$ indicators. The operator should not input any data or touch the keyboard until one of these input indicators has been issued by the program. After typing in the indicated information the RETURN button on the keyboard is depressed.

If an error is made in typing the data input, it can be corrected only if the RETURN button has not been depressed. This is done by using the SHIFT and $\overline{0}$ button to erase each error character. If the RETURN button has already been depressed, it should be depressed again and an (*) will appear. The step is restarted by using the GOTO table listed at the back of the instructions for the required step. The GOTO will restart the particular section. In cases of restarting CEPH 2, CEPH 3, and 'CEPH 4 this can be accomplished by going back to the (DFM) disk file manager and executing the appropriate command (E, CEPH 2, E, CEPH 3, E, CEPH 4). In the case of CEPH 1 restarting from DFM will necessitate the reentering of the digitized data. Thus, in CEPH 1 if this data is already entered, it is better to go back to the GOTO table to restart a decision step.

Copies of each step may be obtained using the Tektronix 4610 copy unit. The copies should be made prior to indicating that the step is complete $($ Yes $=1)$. This is done by depressing the copy button on the Tektronix 4010 terminal and waiting until the copy is made on the copy unit. Once the copy has been produced, then the operator may indicate that the step is complete.

An abbreviated list of the procedure to use the treatment planning program is included for quick reference. The table of error GOTO's should be helpful in enabling the operator to recover from errors in each step. 


\section{Error Restart - GOTO's}

Location

CEPH 1

CEPH 2

CEPH 3

CEPH 4
Type of Error

Digitized data

Correction of data

Growth prediction

Cant of occlusal plane

Rotation of Mandible

Level of occlusal plane

Profile selection

Tissue thickness update

Lower incisor position

Command Input
Enter

GOTO

GOTO

1005

GOTO

1007

GOTO

1014

GOTO

1018

GOTO

1100

GOTO

120]

GOTO

1100

GOTO

1250

GOTO

1272

GOTO

Note

1. To correct one character input use SHIFT and $\underline{\overline{0}}$ to delete character.

2. If an entire section other than CEPH 1 is to be repeated, then use DFM command with appropriate input, i.e., E, CEPH 2.;

E, CEPH 3.; E, CEPH 4.. 
Instructions for Using the Orthodontic Treatment Planning Program

1. Turn on equipment and check to see that all equipment interconnections are properly connected.

2. Turn off the PROTECT button on the disk unit.

3. Depress the SENSE switch on the computer panel to the down position.

4. Place the lateral headplate tracing on the digitizer tablet and check for alignment of the FH line with the $X$ axis.

5. Enter $59 \subset \emptyset$ (Hexadecimal) in the computer program register.

6. Depress the STOP $\rightarrow$ RESET $\rightarrow$ ENTRY $\rightarrow$ RUN buttons on the computer front panel. The disk file manager should appear on the Tektronix 4010 display $(>)$.

7. Type E, CEPH 1. The display should return with (*).

8. Type RUN and depress the RETURN button on the Tektronix 4010 keyboard.

9. The program will now lead the operator through the rest of the Treatment Planning Program.

10. NOTE: Each entry must be followed by the operator depressing the RETURN button on the Tektronix keyboard. 
BIBLIOGRAPHY 


\section{REFERENCES}

1. Faber, R.D. Computers in dentistry. unpub1. Univ. of Md. 1972.

2. Rocky Mountain Data Systems. RMDS computerized cephalometric manual. second ed. Aug. 1972.

3. Cleall, J.F., Chebib, F. Coordinate analys is applied to orthodontic studies. Angle orth. 41:3 214-218 July 1971.

4. Walker, G., Kowalski, C.J. Computer morphometrics in craniofacial biology. Comput. biol. med. 2:235-49 1972.

5. Solow, B. Computers in cephalometric research. Comput. biol. med. $1: 41-491972$.

6. Krogman, W.M. Use of computers in orthodontic analysis and diagnosis: a symposium. Am... J. ortho. 61:3 219-254 March 1972.

7. Walker, G. Cephalometrics and the computer. J. dent. res. 46:1211 Nov-Dec 1967.

8. Ricketts, R.M: The evolution of diagnosis to computerized cephalometrics. Am. J. ortho. 55:795-803 1969.

9. Solow, B. Automatic processing of growth data. Angle ortho. 39:186-97 July 1969.

10. Currier, J.H. A computerized geometric analysis of human dental arch form. Am. J. ortho. 56:164-69 Aug. 1969.

11. Briggerstaff, R.H. Computerized diagnostic setups and simulations. Angle ortho. 40:28-36 Jan. 1970.

12. Brader, A. Dental arch form related with intraoral forces: $P R=C$. Amer. J. ortho. 61:6 541-61 June 1972.

13. Walker, G., Kowalski. A two dimensional coordinate model for the quantification, description, analys is, prediction, and simuiation of craniofacial growth. Growth. 35:191-211 1971.

14. Savara, B.S. Use of computers techniques in the study of growth. Adv. oral biol. $4: 1-91970$.

15. Parin, V.V., Bayevskiy, R.M. Introduction to medical cybernetics national aeronautics and space administration, NASA TT F-459 JuTy 1967.

16. Greenberg, L.Z., Johnston, L.E. Computerized prediction: The accuracy of a long range forcast. Am. J. ortho. 67:3 243-252 1975.

17. Shulohof, R.J., Bagha, L. A statistical evaluation of the Ricketts and Johnston growth forcasting methods. Am. J. ortho. 67:3 258-276 1975. 


\section{TABLES AND FIGURES}




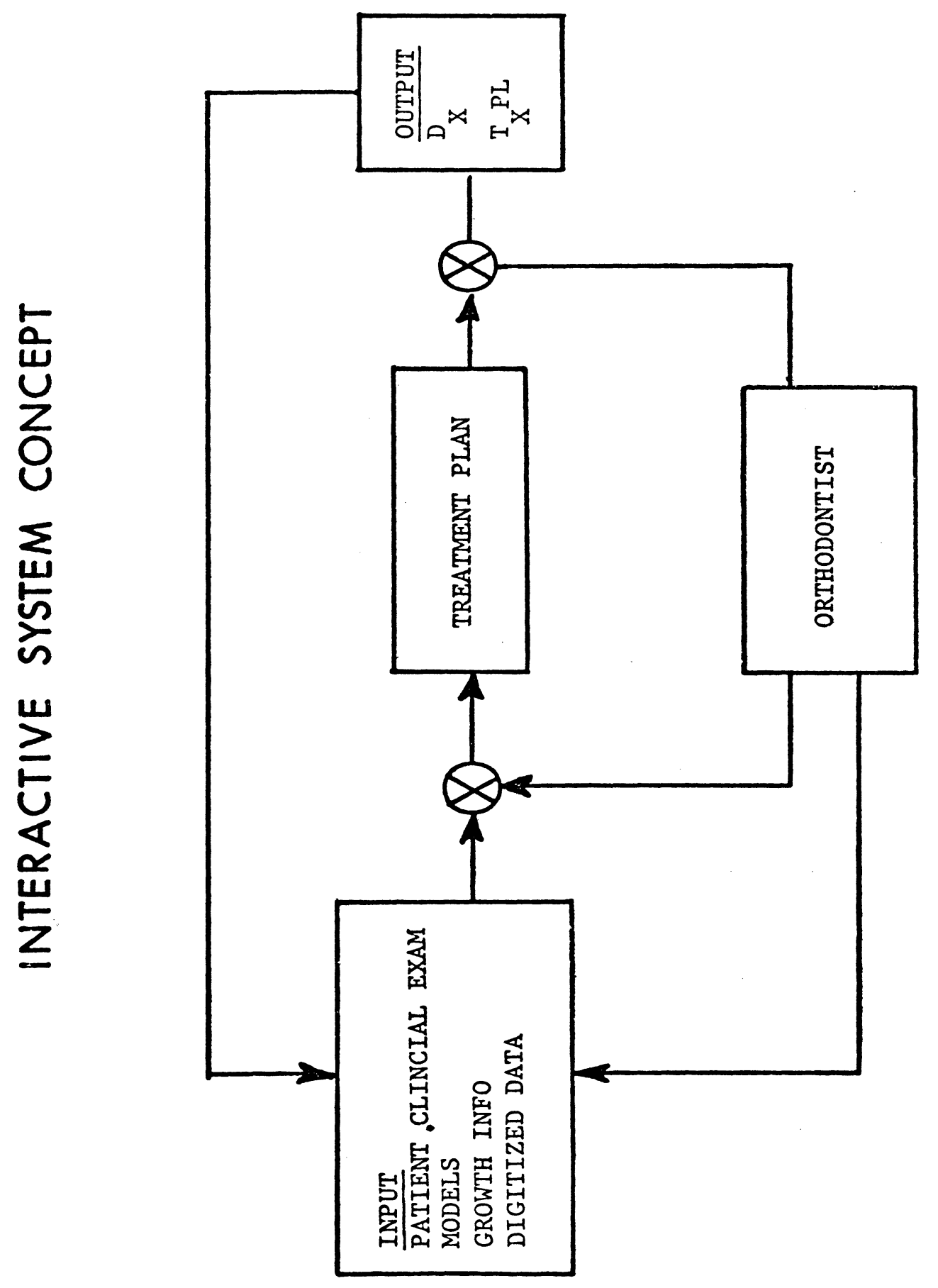

$\stackrel{-\sigma}{i}$ 


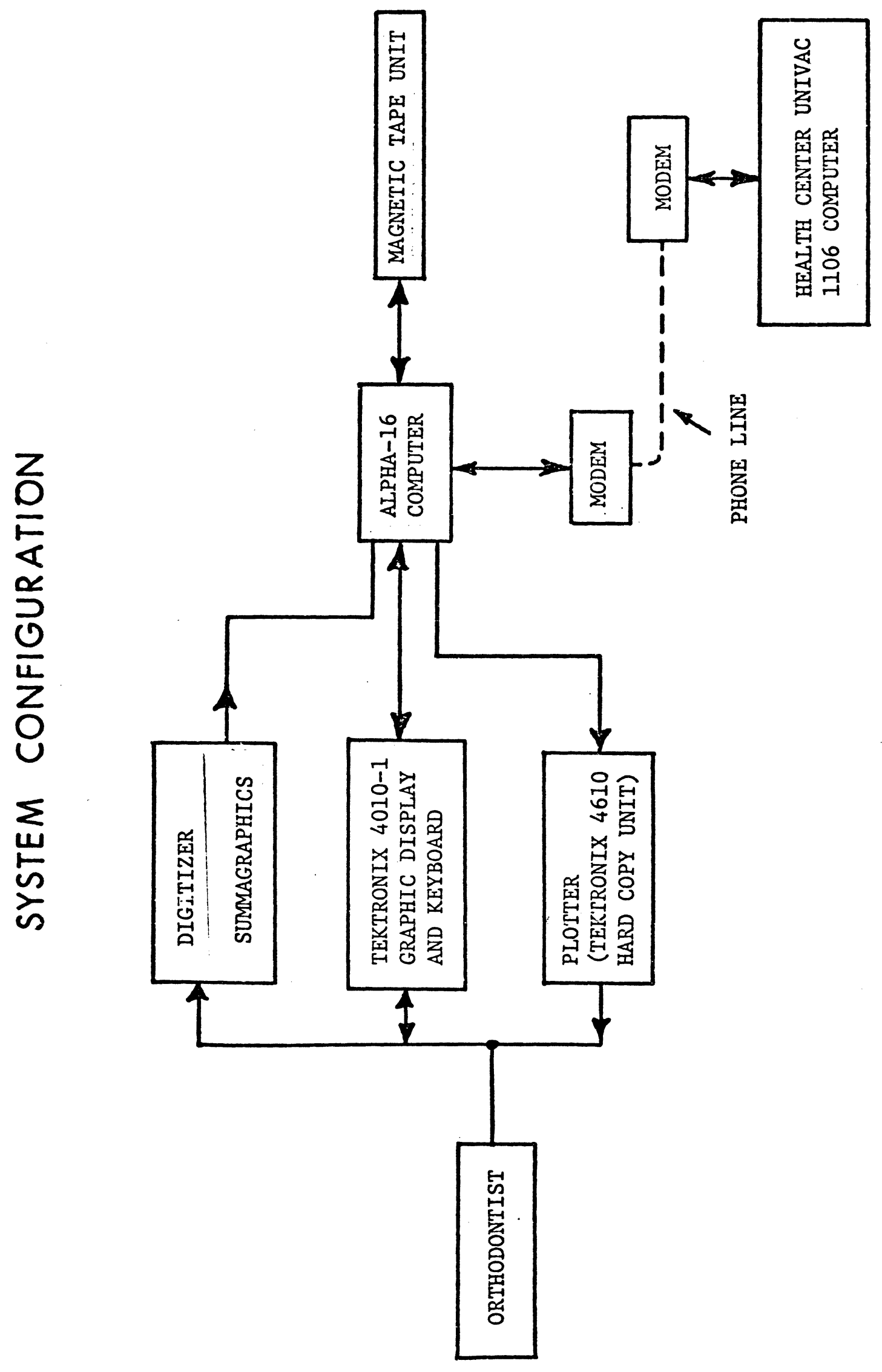

$v$
$\dot{n}$ 


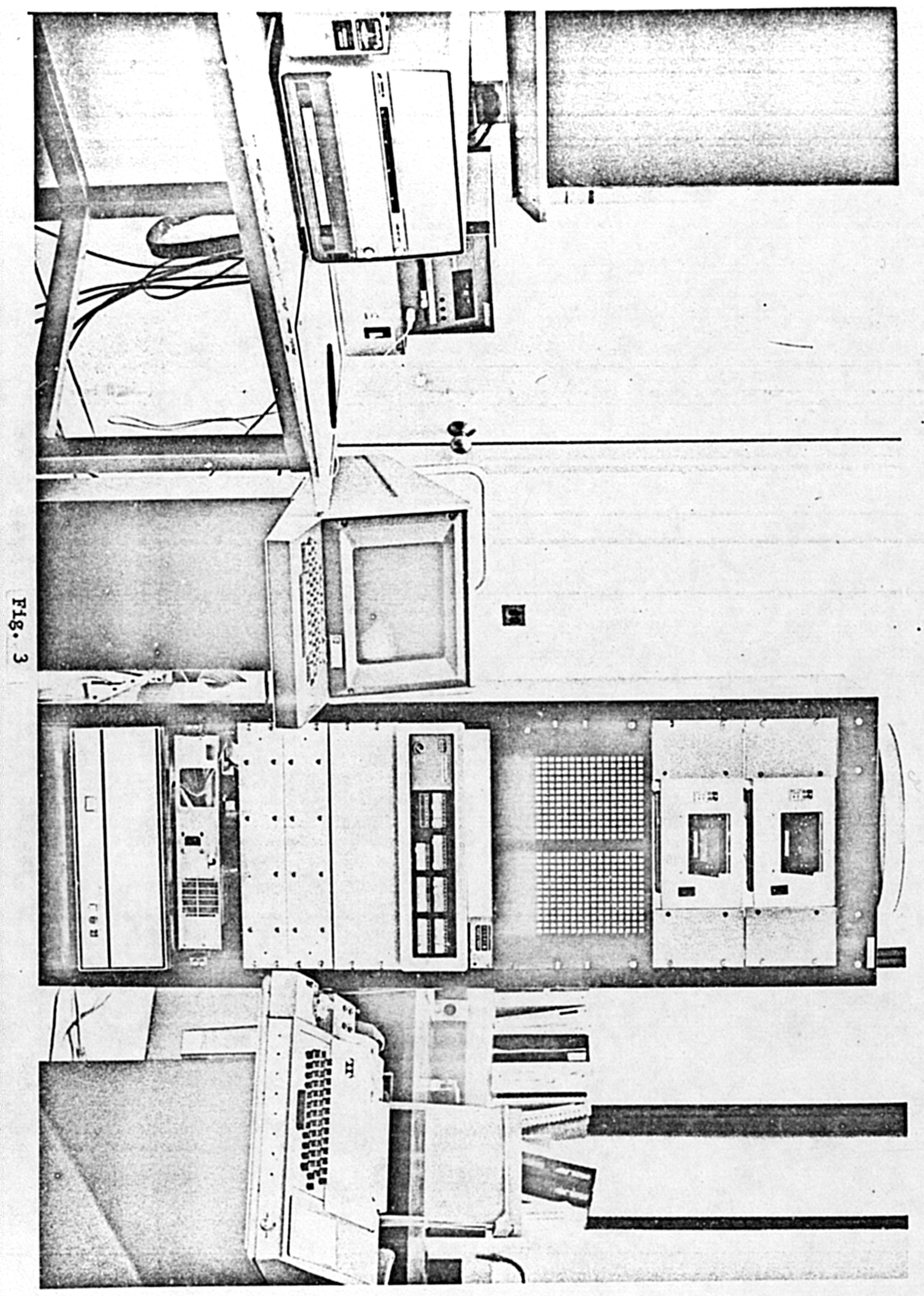




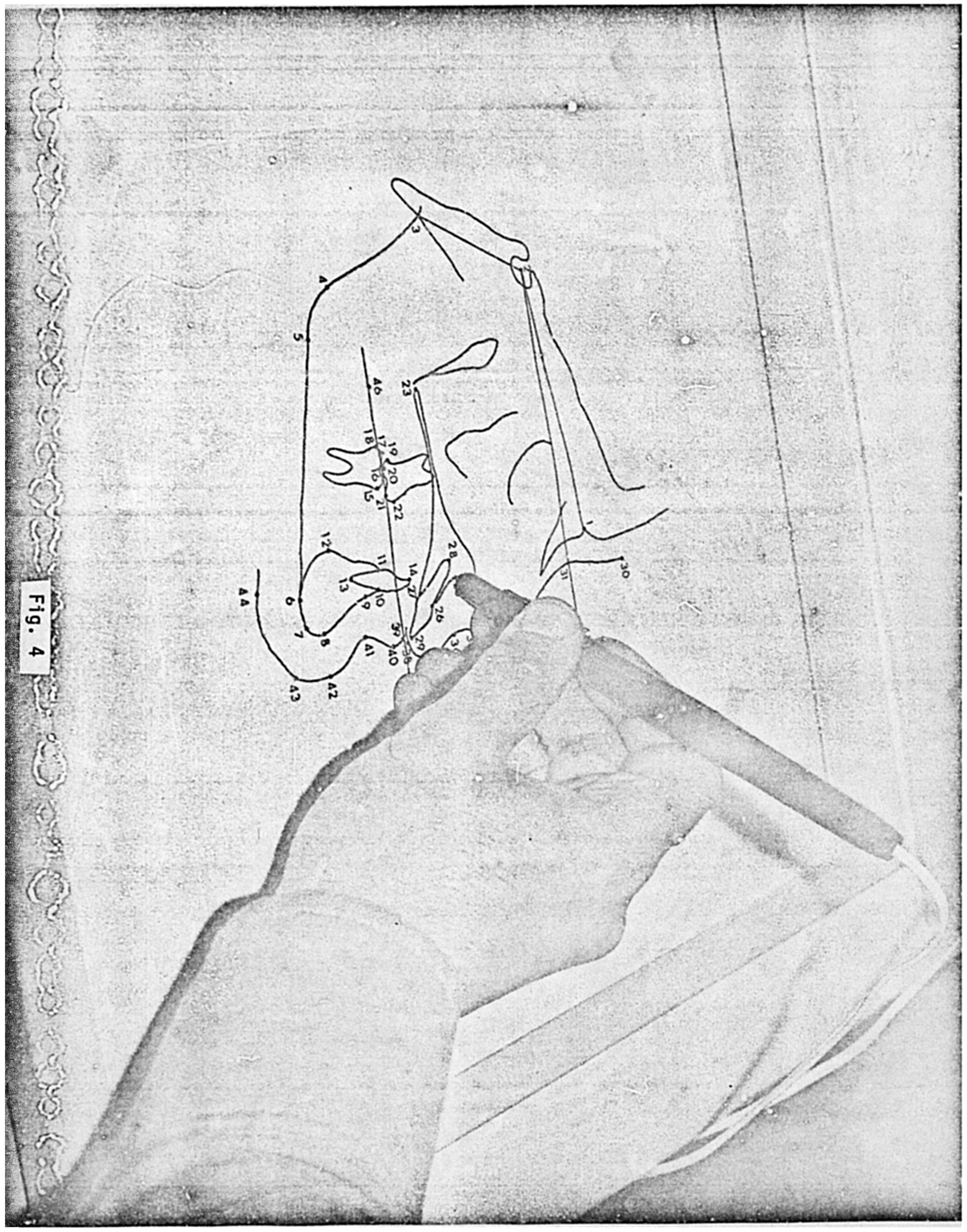




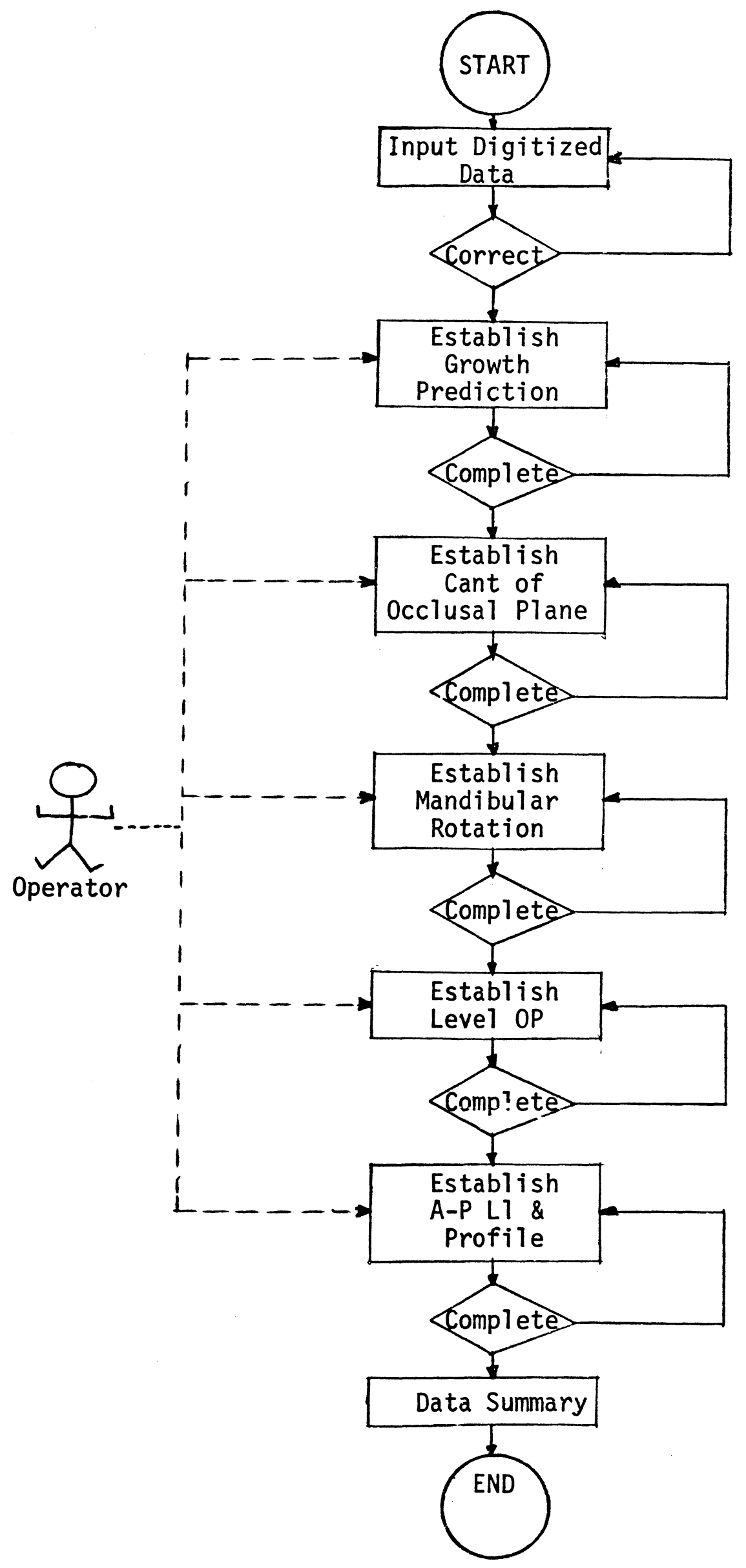

Fig. 5.0 


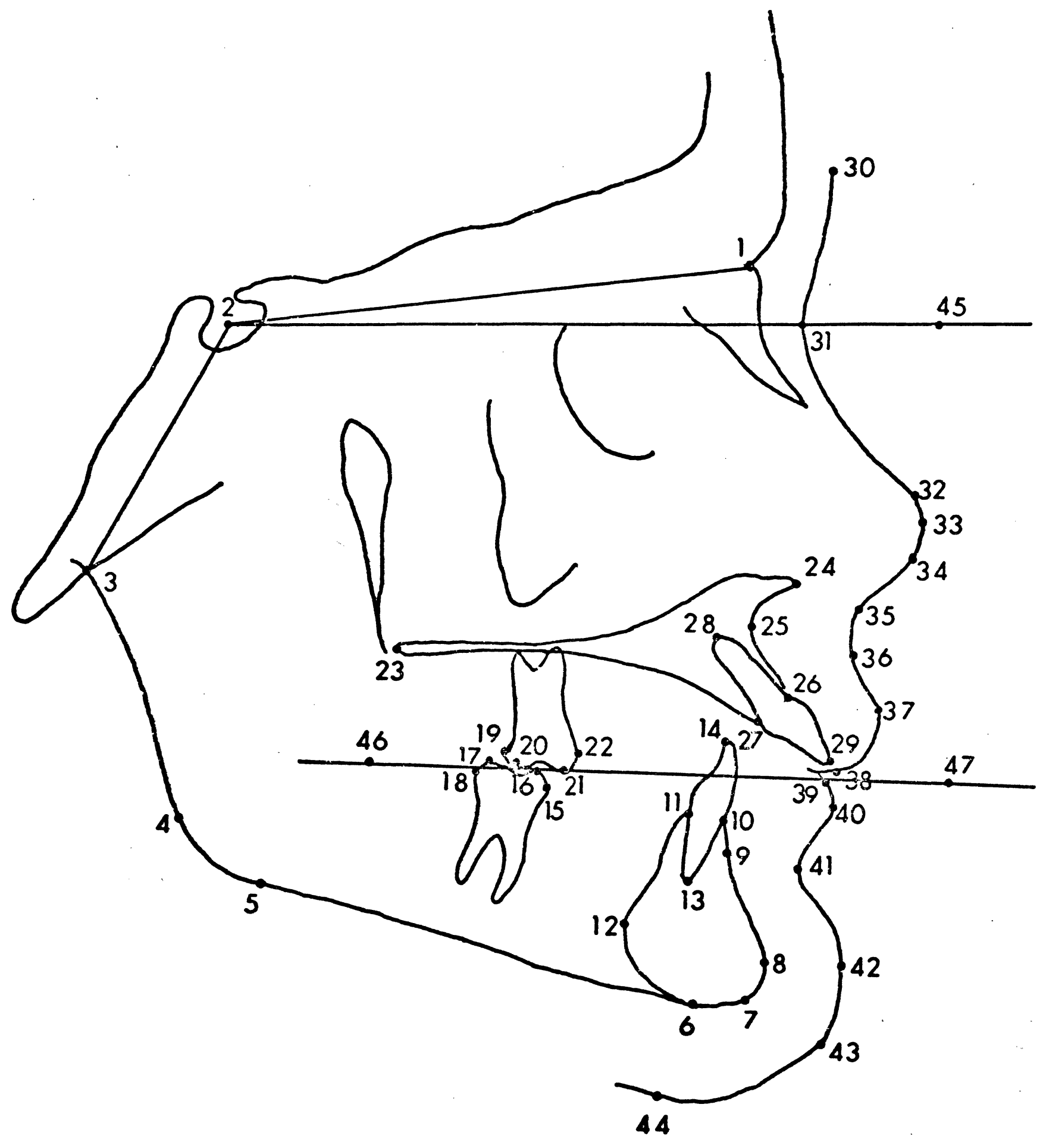

Fig. 6 
IHPIJT OIF DATA FFIMM MIGITEEF

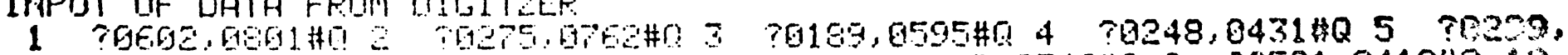

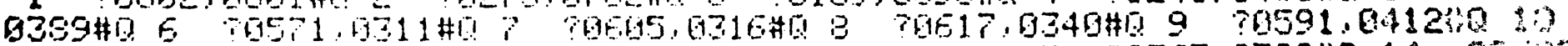

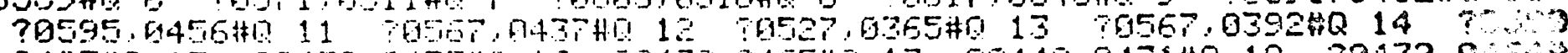

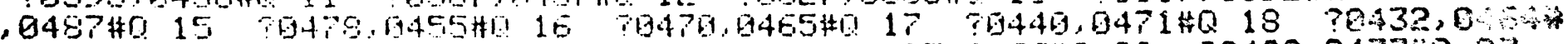

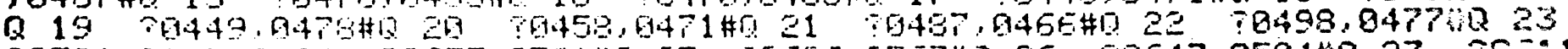

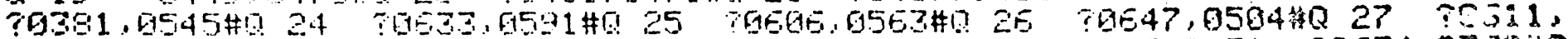

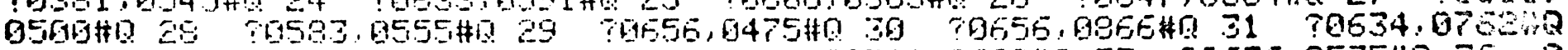

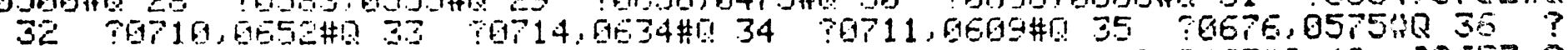

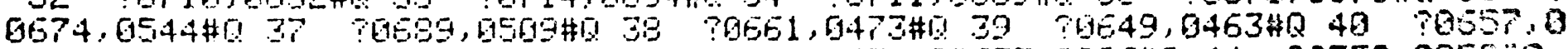

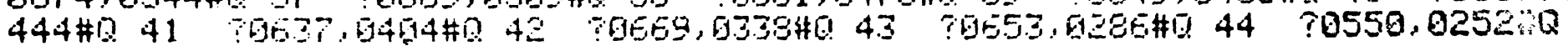

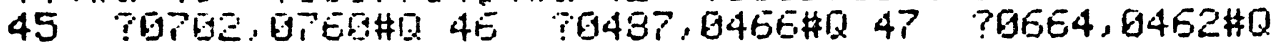

CORPECTINHA DF DIGITIZEO DATA

OO YOU WISH TO MAKE EOFEECTIOHSS YES=1/HO=0)

$? 1$

INPUT I ( IF COJRFECTIOHE COMPLETE LET I=9999)

$? 47$

REDIGITIZE

?06.53, $0463 \#$

IHFUT I (IF COFFECTIDHS COMPLETE LET I=9999)

?9999

Fig. 7 
1.0 ESTABLISH GFINJTH FREGIOTIOH

USE GROHTH FREUICTIOH TAELES-EHTEF YF IHCR FOR 2 YRS

IHPUT SIH IHCFEMEHTS

$? .39$

7.96

IHFUT FHE-ANE(FH).H-ANS(FFH)

?1. 04

$? 1.04$

?.>?

$? 1.59$

IHFUT $Y$ ASIS,Y ANGLE

?2. 25

$? 3.43$

753.0

Fig. 8 


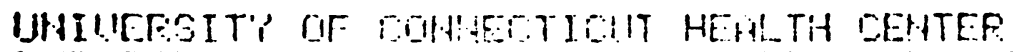

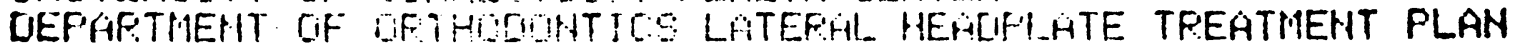

2.9 DATA BHEE TO EETGELISH CAHT DF TICELIJSAL FLAHE

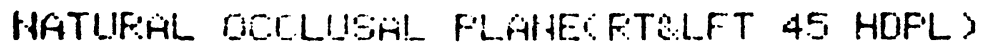

A HODIF HOIAL 1HLLIHATIOHS

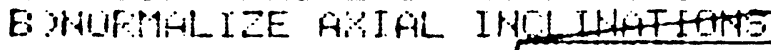

ESTHETIS: DICLLIGAL FLAHEYLIF LIHE)

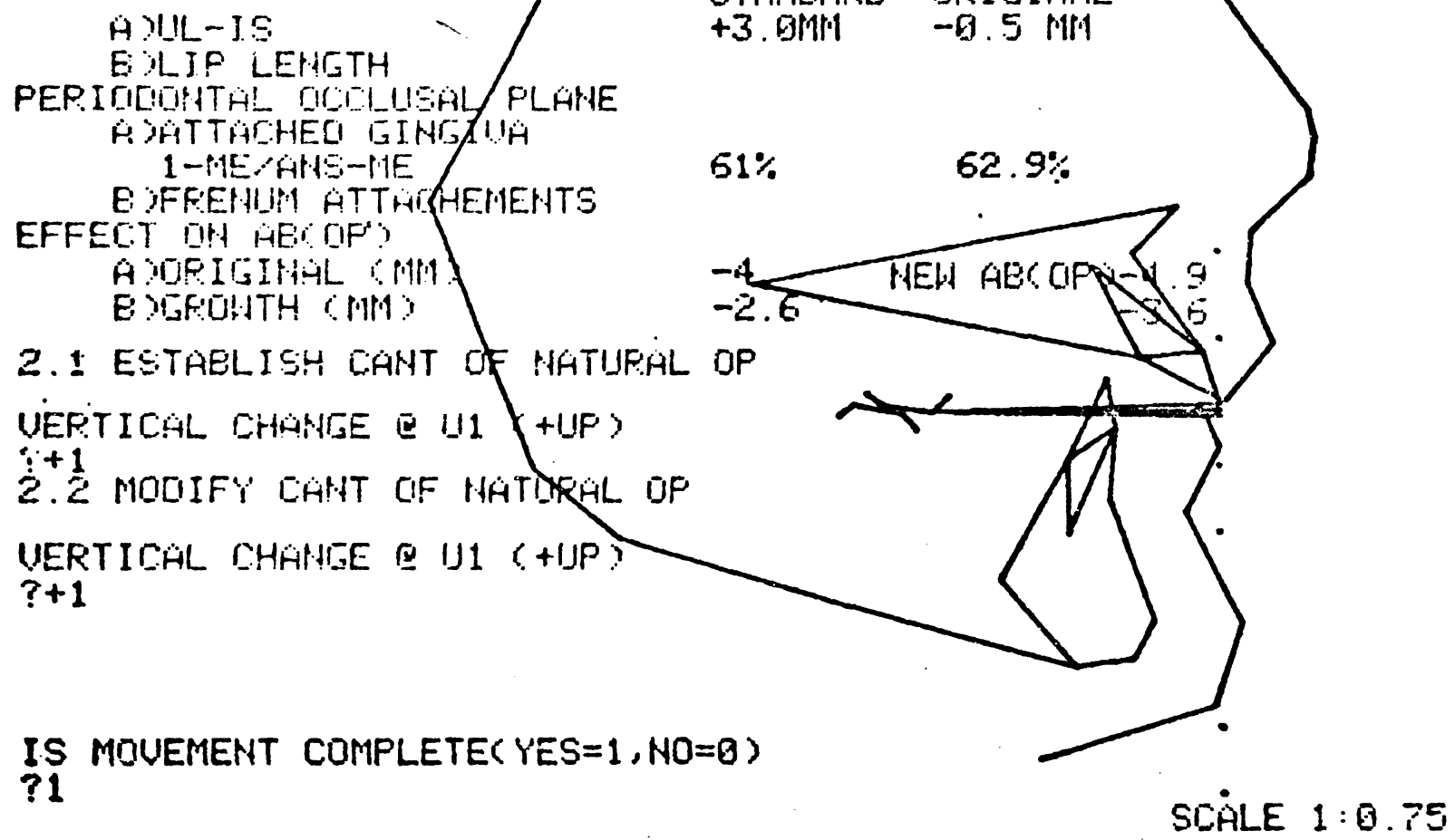

Fig. 9 
UHIUEFSITY RIF ROHHETTIEIT HFHATH RFHTER:

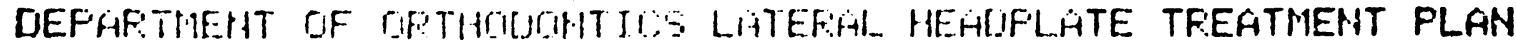

3.9 DATA EHSE TO ESTHELISH MAHOIEULFF FOTHAIOH

UERTIRAL COHEILEFATIONS

HDH HS-PIE H-THE

E) IPTSFLAESHL LAF

C) HTEFTAILLAEY OF FFEEWAY SFACE

HORIZOHTHL COHSIDEFATIDHS

A TAECOC O

EDFFOF ILE H-A-PG

HEUFCHUSCULHF STAEILIT'Y COHSIDERATIONS

CHAHHES FELATIUE TA GFOHTH AHD ROTATIOH

HEW ABC OF CMKS

MEW H-A-FI COEE?

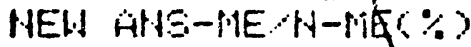
STAPHDHFO DFIIIHAOL

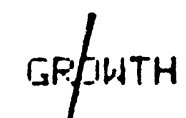


UHIUEFSITY OF ROHHFTIOUT HEOLTH CEHTEF

DEFGFTMEHT GF DR? HULOHTJSS LATERAL HEAUPLATE TREATMENT PLAN

4.9 DATA EASE TO ESTAELISH LEUEL OF CHOLUSAL FLAHE A) SETHETIRSCLIP LIHE)

E)ATTALHEO LIHISTUA $1-P E+H S-M E$

C)TOHIJE PISITIOH

DDINTEFMARILLAFY GROWTH SFACE IJE.LS UE. URIDY-LECGGT $3.9 \mathrm{MM}$

4.1 ESTAELISH LEUEL \&F DCRLLUSAL PLAHE் UERTICAL CHAHGE MM + +D? ?-1. 2 STAHUARE DFIEIHAL 
UHIUEFSIT'Y DF COHHFITIOUT HEHLTH EEHTEF

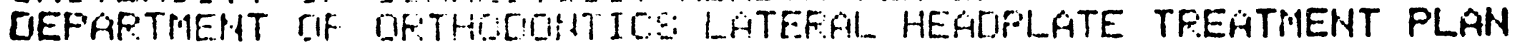

5.0 DATA BASE TO ESTAELISH A-F POSITIOW OF LOWEF IHCLSDR

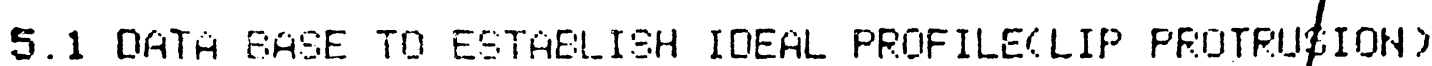

A NHOSE FOIFM AHLI SILE

E HASIOLFEIAL HHLL

CDFACIAL COHUESITY

G OUEFTICHL HEIDHT FALE

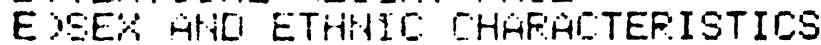

5.2 ESTAELISH ILIEAL FFIIFILE

LL FFOTFUSIOH THAHISE MPI + ? $?+3$

UL FFOTFUSIOH CHAHIIE MM $+>$

?-2 ESTAELISH CCIFEETTIOHS FOR SOFT TISSIUE RIRAPE [IO YOU WISH TO CORFECT LL THICKHEST YES $=1, H O=G$ )

?1

IHFUT LL THICKHESS IH MH

$? 12.0$

UO YOU HISH TO CORPECT UL THICKNESSR YES=1, HD=0? ?1

INFUT UL THICKTESS IH MH

?11.0

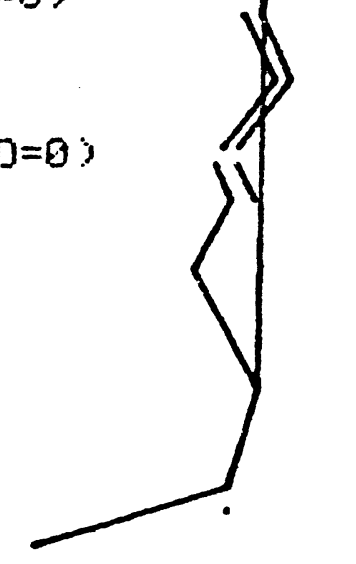

IS MDUEMEINT COMPLETES $Y$ IES=1, NÜ=0? 
UHIUEFSIT' OF COHHEOTIOUT HEHLTH OFHTER

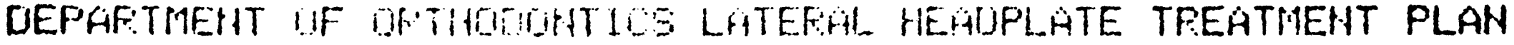

5.9 UATA EASE TO ESTAELISH A-F FOSITIOH OF LDWER IHCASOR

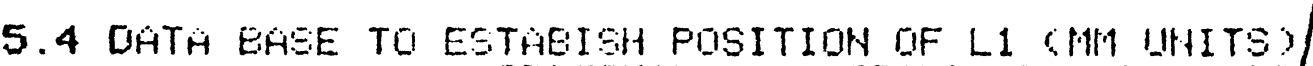

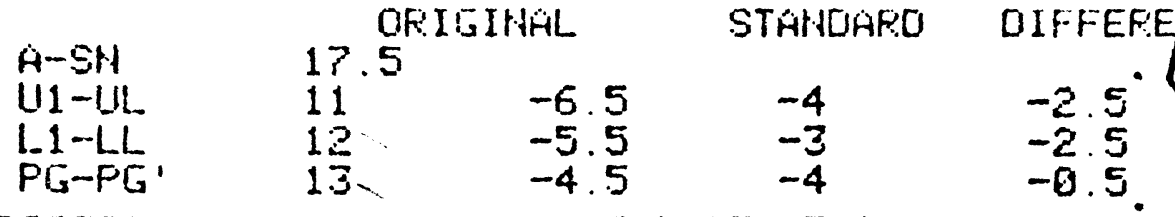

L1 FOSITIONA CHAHIGE TO SUFPORT PROFILE-1

PEFIORAL COHEIUEFATIOHS

A)LIP LEHETH ULYLL

EOLIF DOMFETSHCY, EASE \& MAHHER OF CLOSUPE

COIHTEFLAEIHLL GAP

DULIF CUIPL CLL

STAEILITY BOHEIUERATIONS

AXLIP [IFAPE

EYTOHGIJE FOSTURE AHD FUHCTIOH

C. HABITE

5.5 ESTAELISH COFEECTIOHS TO LI POSITIOH

L1 PDEITION CHANISE MI +>

UI FOSITIOH CHAHTE MM +

$7-5.8$

IS MOUEMENT COMPLETE( YES $=1, H D=0$ )

?.1

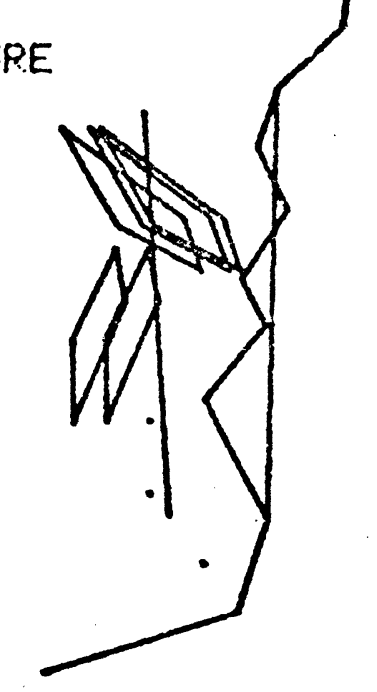

Fig. 13 
WNIUERSITY OF CDHHECTICIT

TREGTMEHT PLAH SUMMAFU FFOH LATEFAL HEAOFLATE

SKELETAL ALTERATIONS

HOFIEONTAL AECTROP?

UERT ICAL AHSS-MEYH-HE)

$$
\begin{array}{ccc}
\text { ORIGINAL GROWTH } & \text { GROWTH+ROTATION } \\
-4.9 \% \mathrm{MH} & -3.6 \mathrm{MH} & -2.9 \mathrm{MM} \\
57.1 \% & 56.7 \% & 55.3 \%
\end{array}
$$

OCCLUSAL PLANE (TYOP)

C.ANT

LEUELGOFIG H-ANT DP S

LENEL (H) GRONTH)

A-P FOSITIOHSTO ORIGIHAL)

UPPER LIP CHAHISE

LOWER LIP CHAHISE

LOWER INCISOR.

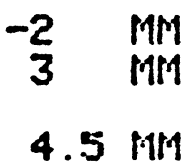

IF TX PLAN CONPLETE IMPUT 1

?1

Fig. 14 


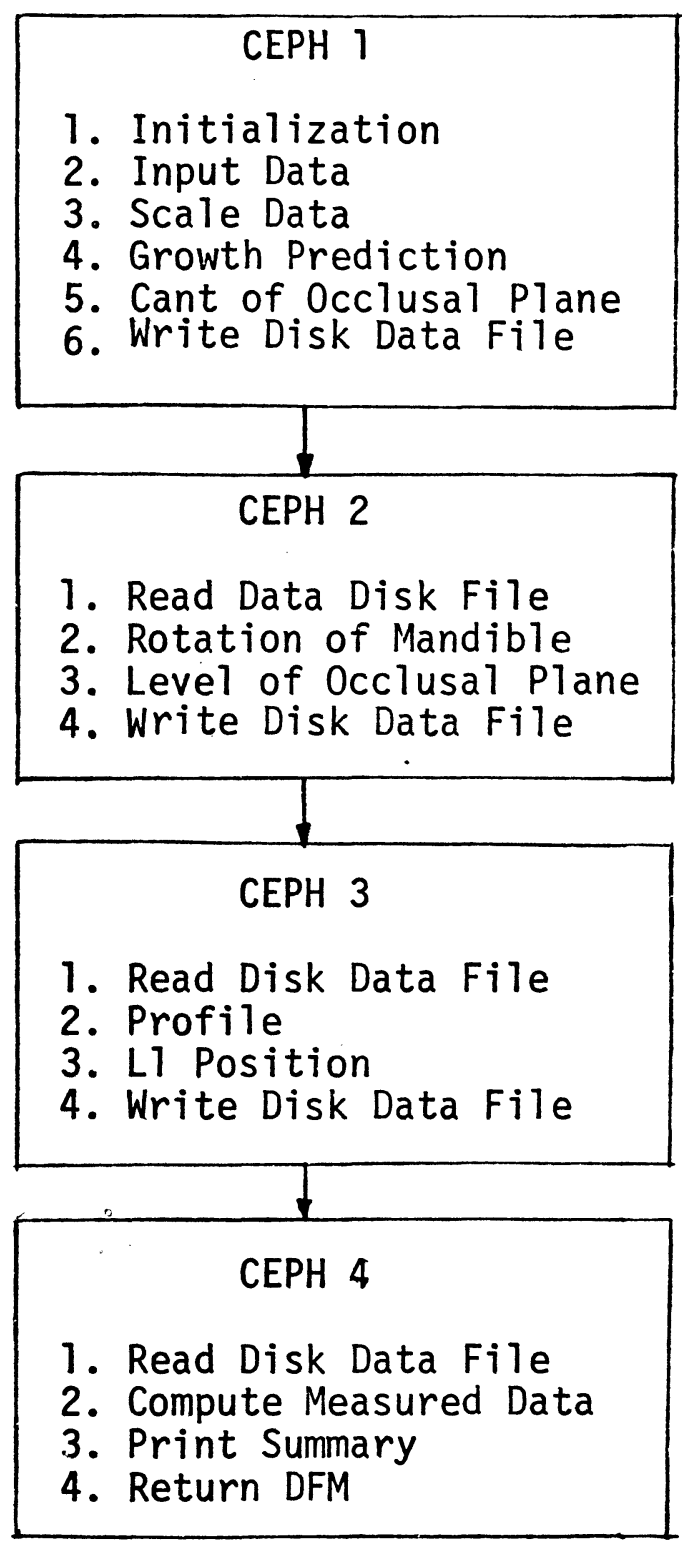

Fig. 15 


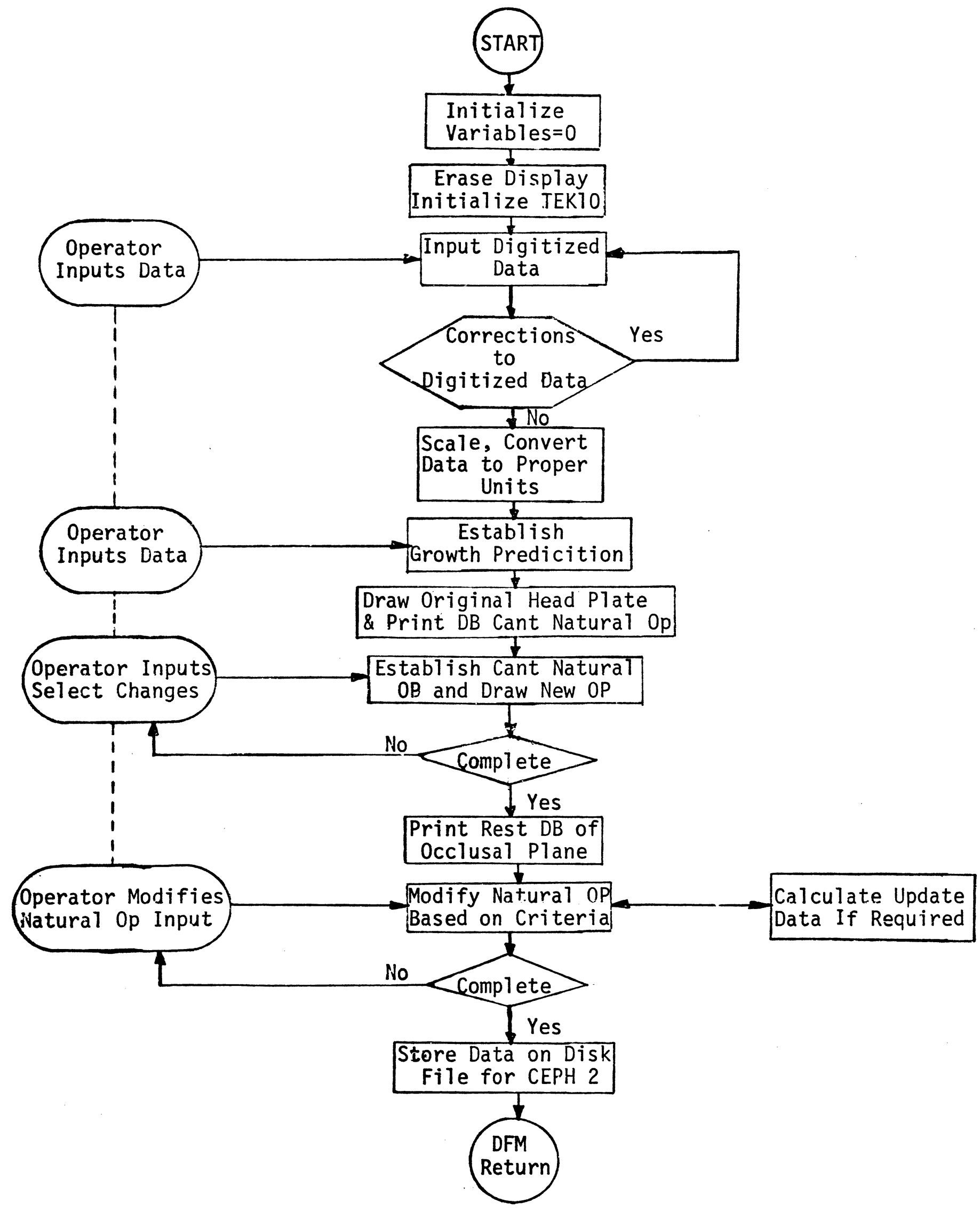

Fig. 16 


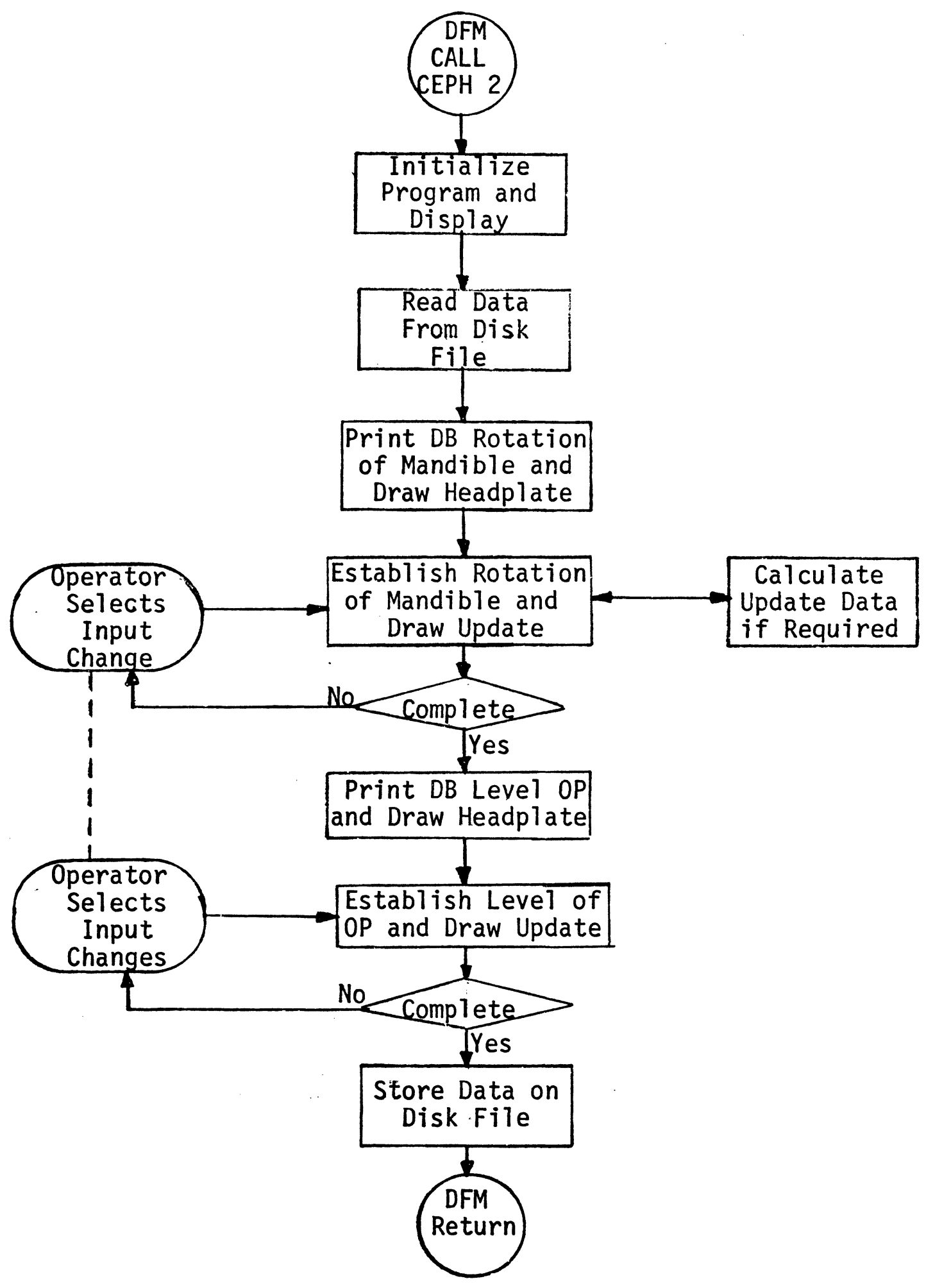

Fig. 17 


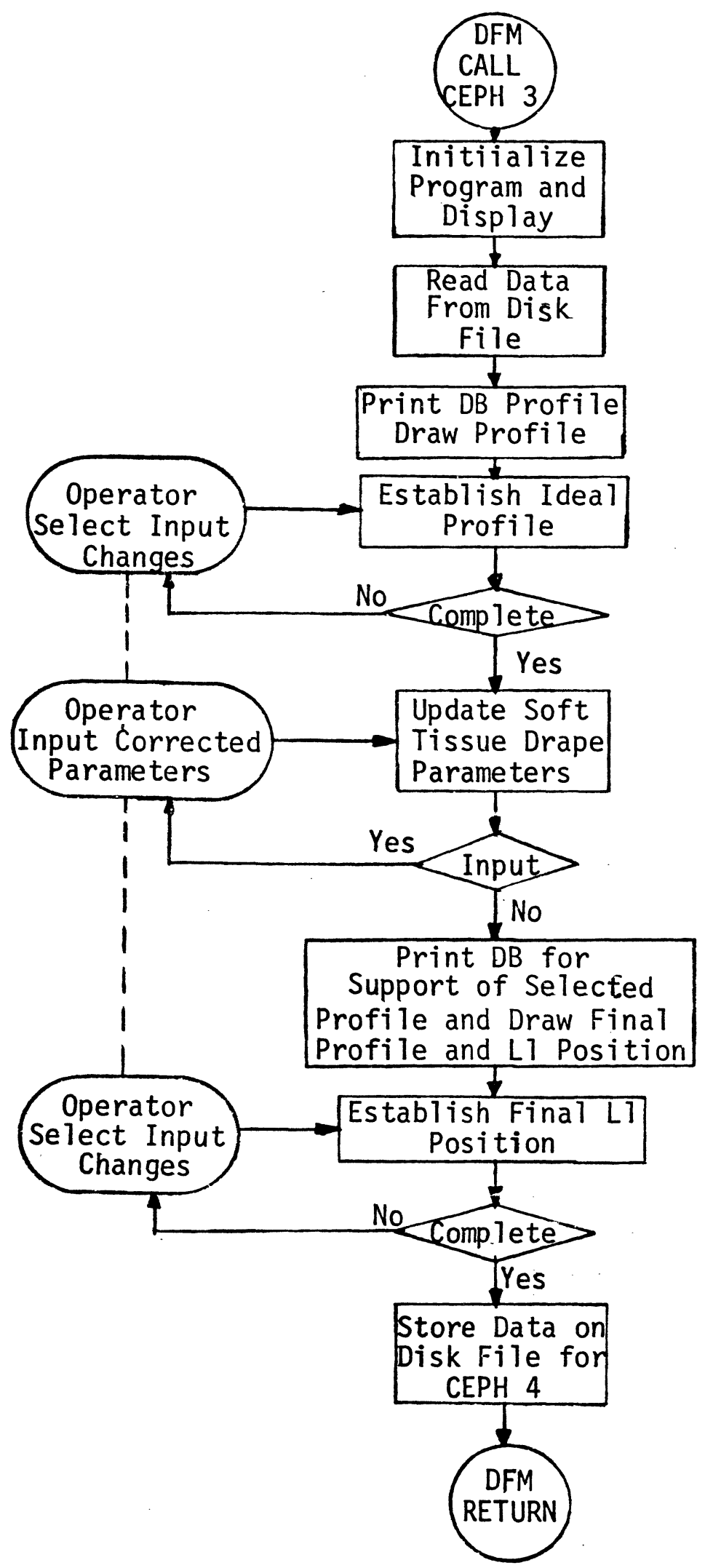

Fig. 18 


\section{FLOW CHART CEPH 4}

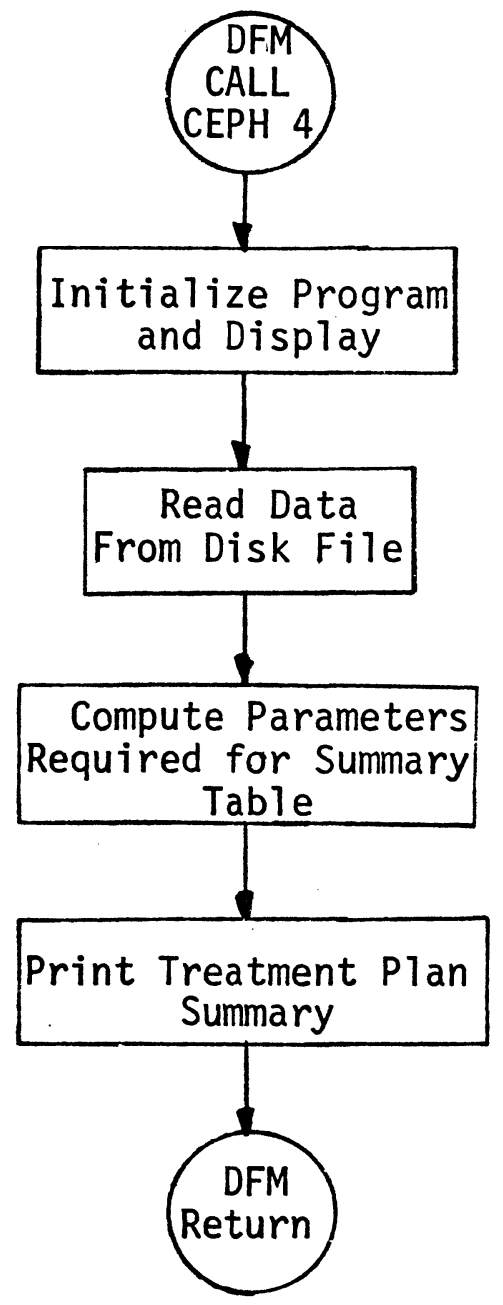

Fig. 19 
S-N Prediction

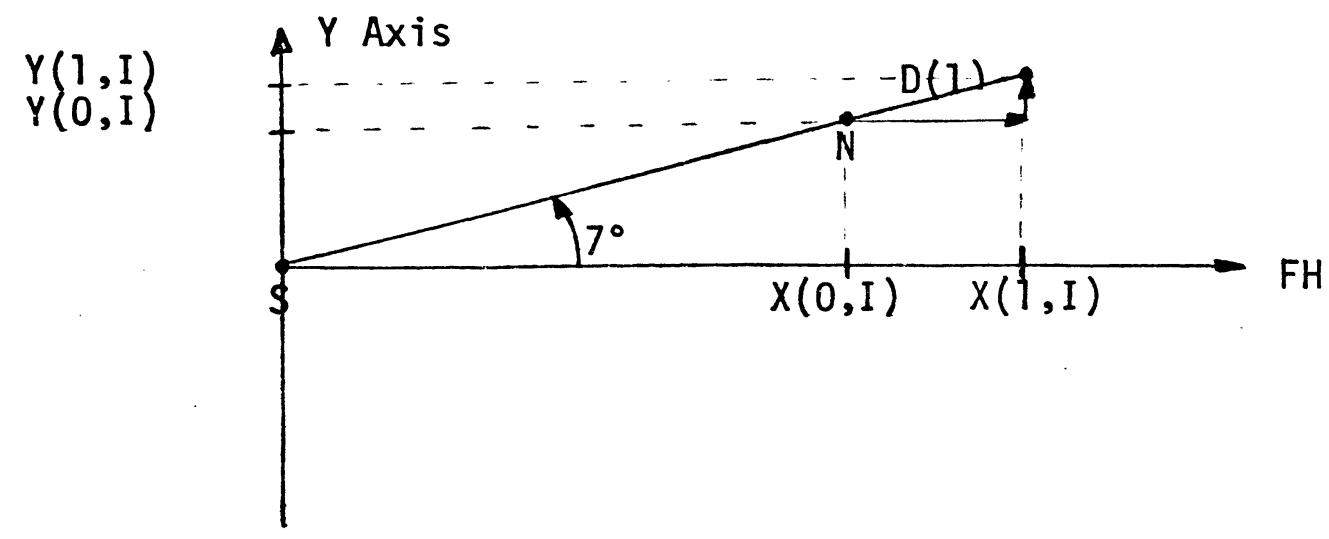

$D(1)=$ S-N Growth Total and Increment

$D(2)=$ Input Growth Increment

So

$$
D(1)=D(1)+D(2)
$$

Thus

$$
\begin{aligned}
& X(1, I)=X(0, I)+D(1) * \cos \left(7^{\circ}\right) \\
& Y(1, I)=Y(0, I)+D(1) * \operatorname{SIN}\left(7^{\circ}\right)
\end{aligned}
$$


Mid-Facial Prediction

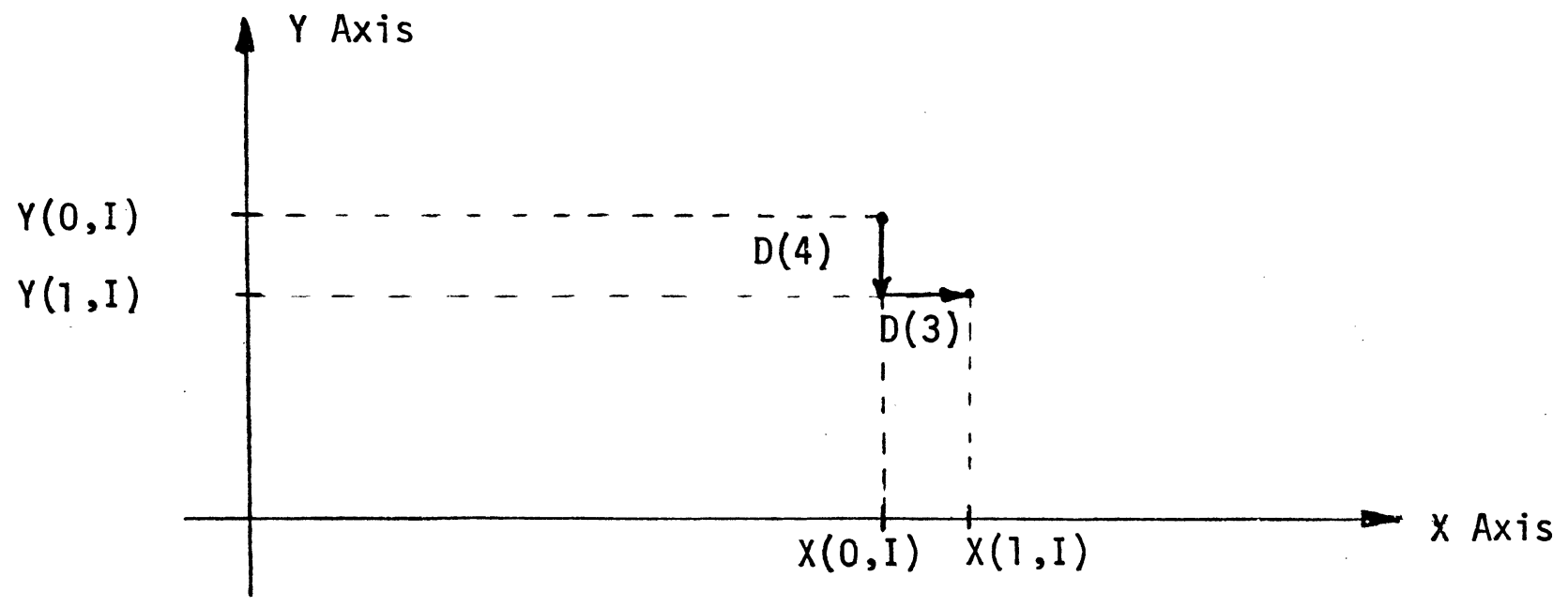

$D(3)=$ Horizontal (A) Growth Increment

$D(4)=$ Vertical (ANS) Growth Increment

$D(2)=$ Input Growth Increment

So

$$
\begin{aligned}
& D(3)=D(3)+D(2) \\
& D(4)=-(D(4)+D(2))
\end{aligned}
$$

\section{Thus}

$$
\begin{aligned}
& X(1, I)=X(0, I)+D(3) \\
& Y(I, I)=Y(0, I)+D(4)
\end{aligned}
$$


Mandibular Prediction

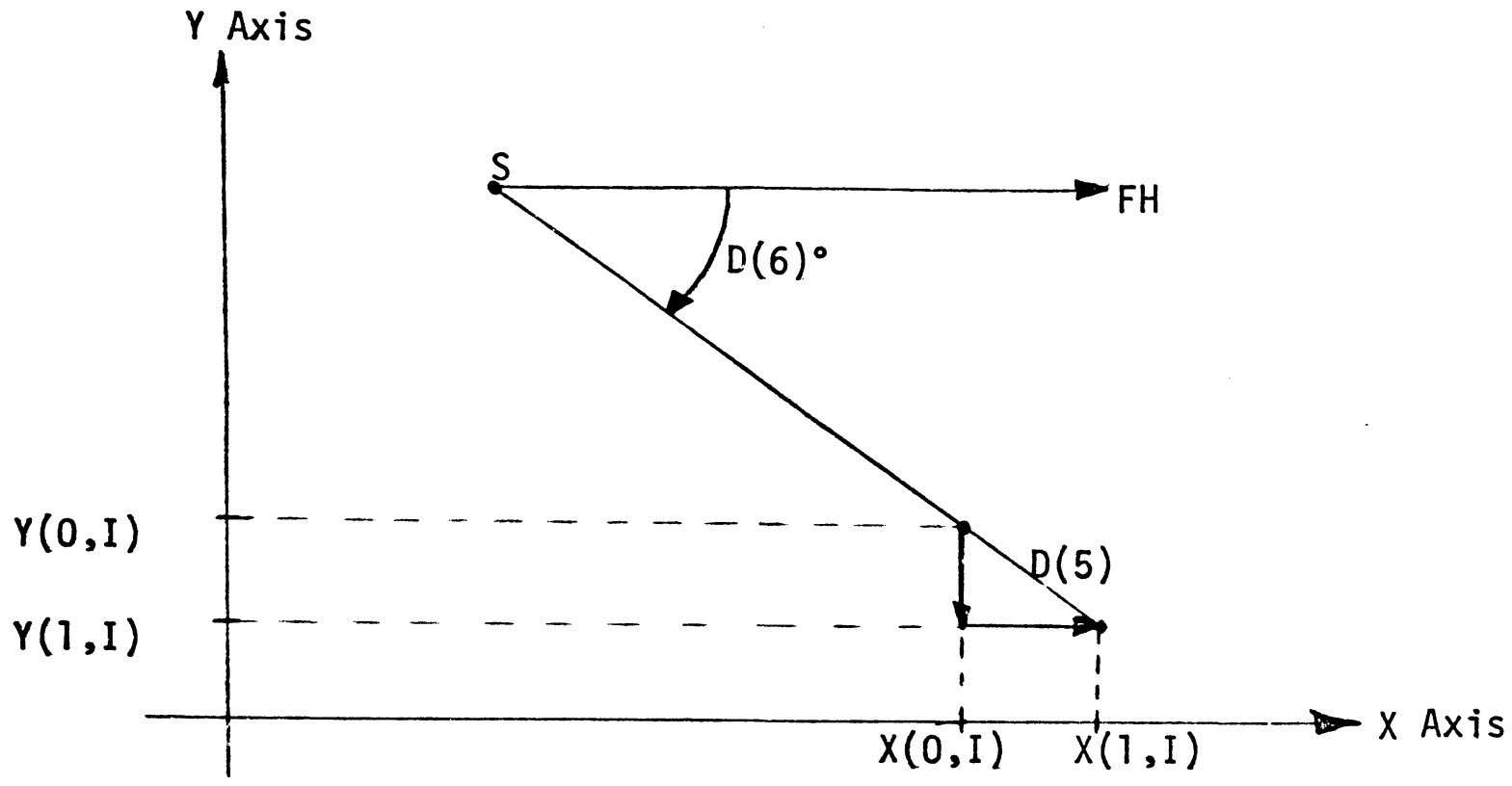

$D(5)=Y$ Axis Growth Increment

$D(2)=$ Input Growth Increment

$D(6)=Y$ Axis Angle

So

$$
\begin{aligned}
& D(5)=D(5)+D(2) \\
& D(6)=D(6)
\end{aligned}
$$

\section{Thus}

$$
\begin{aligned}
& X(1, I)=X(0, I)+D(5) * \operatorname{CoS}(D(6)) \\
& Y(1, I)=Y(0, I)-D(5) * \operatorname{SIN}(D(6))
\end{aligned}
$$

Fig. $20 C$ 


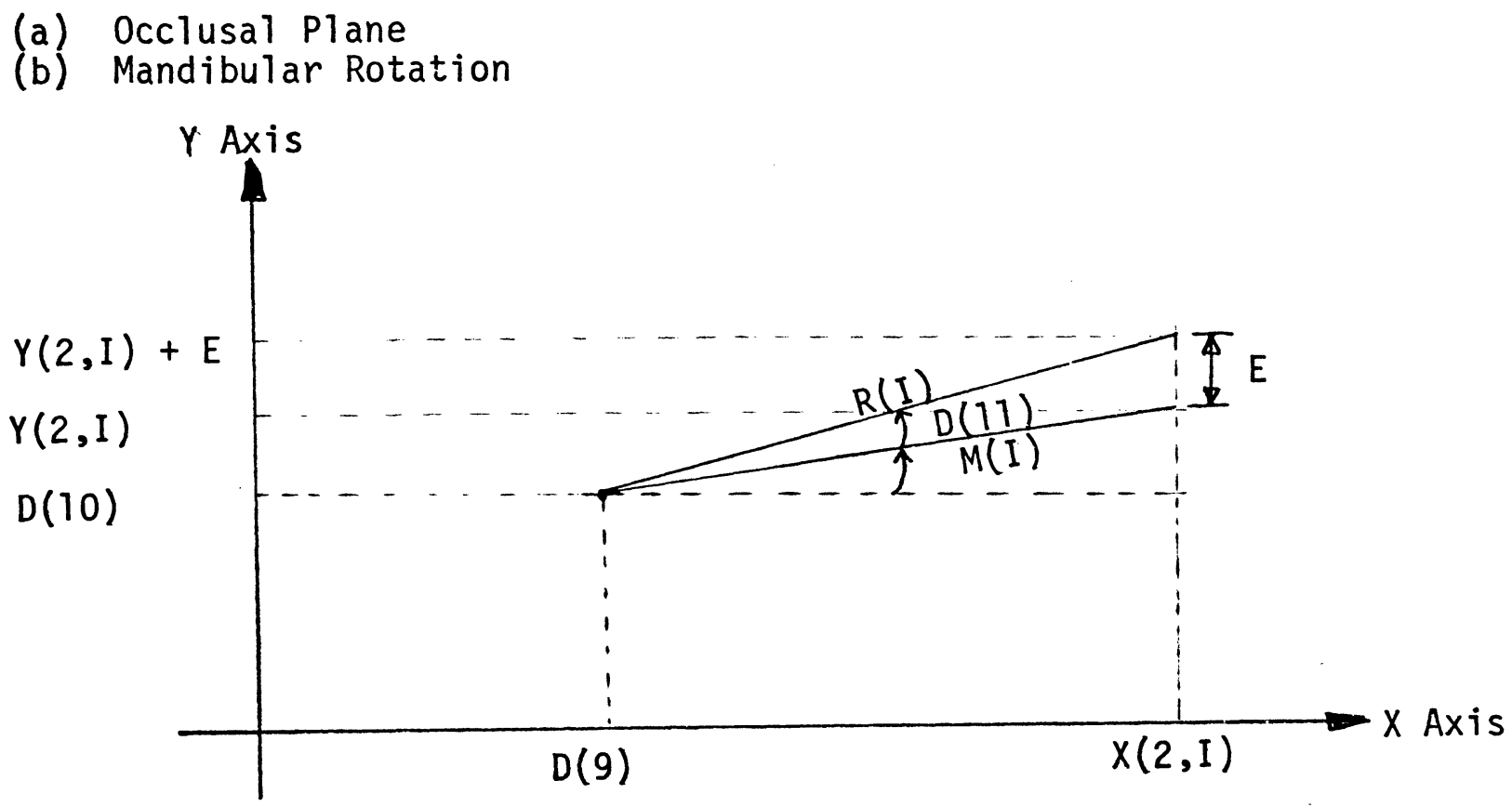

\section{Definitions}

$D(9)=X$ Coordinate of Center of Rotation

$D(10)=Y$ Coordinate of Center of Rotation

$D(11)=$ Angular Change

$R(I)=$ Vector Length

$M(I)=$ Angle

$E=Y$ Increment Change

$F=X$ Increment Change $=\emptyset$

\section{Equations}

$$
\begin{aligned}
& X(J, I)=X(J, I) \\
& Y(J, I)=Y(J, I)+E \\
& R(I)=\sqrt{(X(J, I)-D(9))^{2}+(Y(J, I)-D(10))^{2}} \\
& M(I)=T^{-1}\left(\frac{Y(J, I)-D(10)}{X(J, I)-D(9)}\right) \\
& M(I)=M(I)+D(11) \\
& X(J, I)=D(9)+R(I) * \operatorname{COS}(M(I)) \\
& Y(J, I)=D(10)+R(I) * S I N(M(I)
\end{aligned}
$$




\section{CALCULATION OF ATTACHED GINGIVA RATIO}

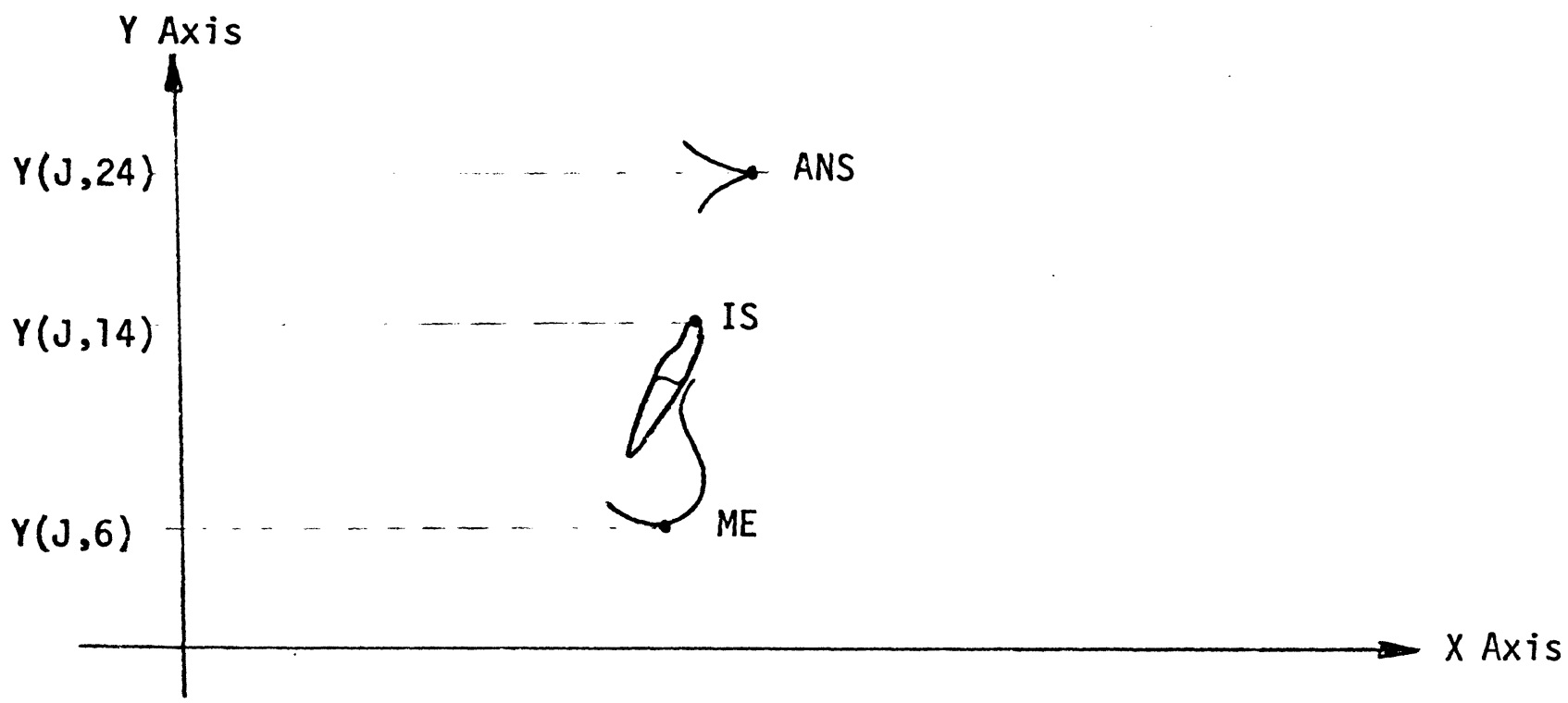

Definitions

$$
N(J, 8)=\text { Measured Value }(J=\varnothing, 1,2)
$$

\section{Equations}

$$
N(J, 8)=\frac{Y(J, 14)-Y(J, 6)}{Y(J, 24)-Y(J, 6)} * 100
$$

Note: Ratio is given in $\%$

Fig. 22 


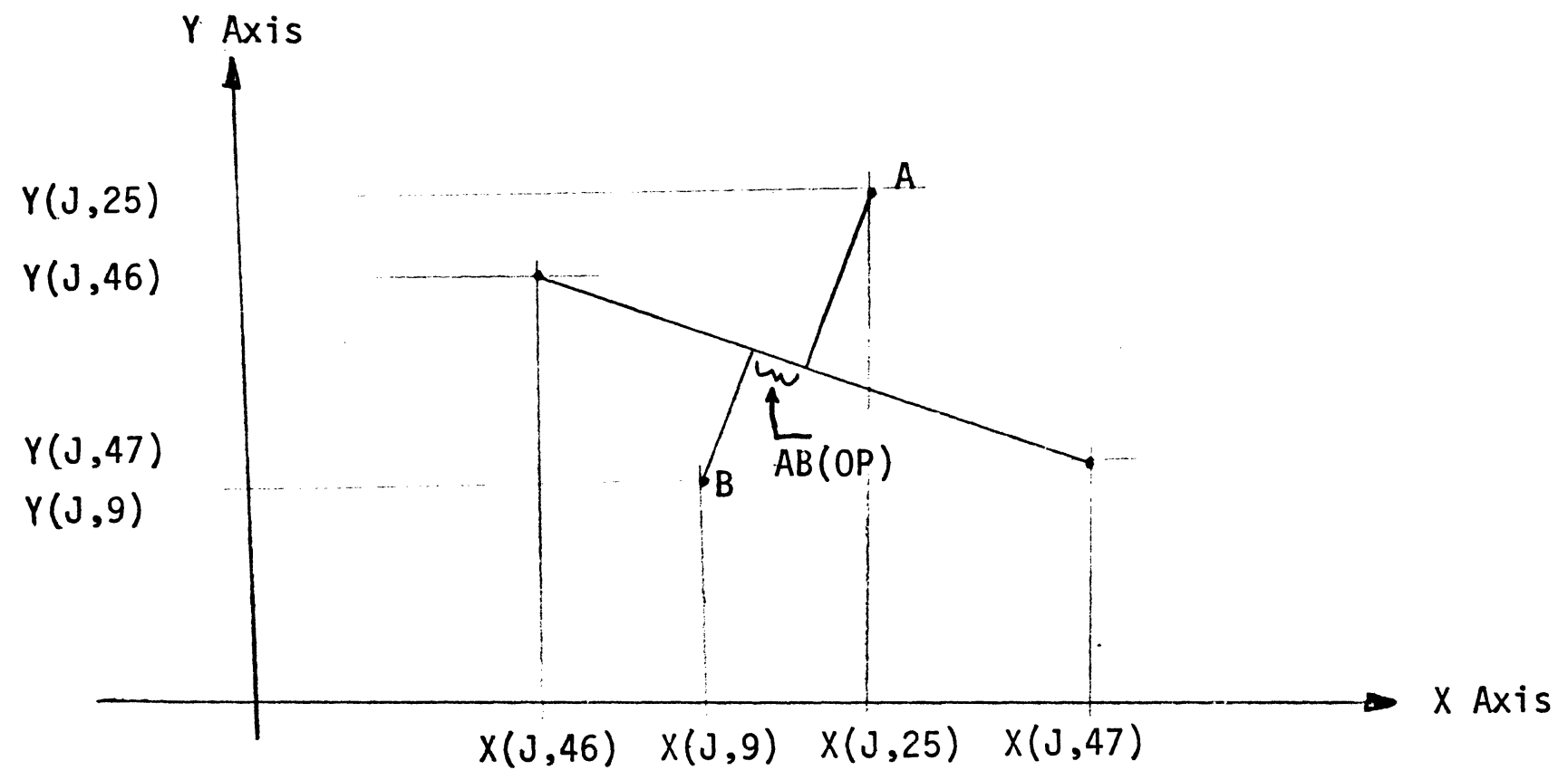

Definitions

$\mathrm{N}(\mathrm{J}, \emptyset)$ Calculation Intermediate

$N(J, 1)$ Negative Slope of Occlusal Plane

$N(J, 2) \quad A-B$ Distance Along Occlusal Plane

$N(J, 16)$ Dummy Used to Check for Divide by Zero

\section{Equations}

$$
\begin{aligned}
& N(J, 1)=-\left(\frac{(X(J, 47)-X(J, 46)}{N(J, 16)}\right) \\
& N(J, 16)=Y(J, 47)-Y(J, 46)
\end{aligned}
$$

Note: If $\mathrm{N}(\mathrm{J}, 16)=\emptyset$ then $\mathrm{N}(\mathrm{J}, 16)$ is set to .001

$$
\begin{aligned}
& N(J, 2)=(N(J, 1) * X(J, 25))-Y(J, 25)+((-N(J, 1) * X(J, 9))+Y(J, 9)) \\
& N(J, \emptyset)=\sqrt{\left.(N(J, 1))^{2}+1\right)} \\
& N(J, 2)=\left(\frac{(N(J, 2)}{(N(J, \emptyset)}\right)
\end{aligned}
$$

Fig. 23 


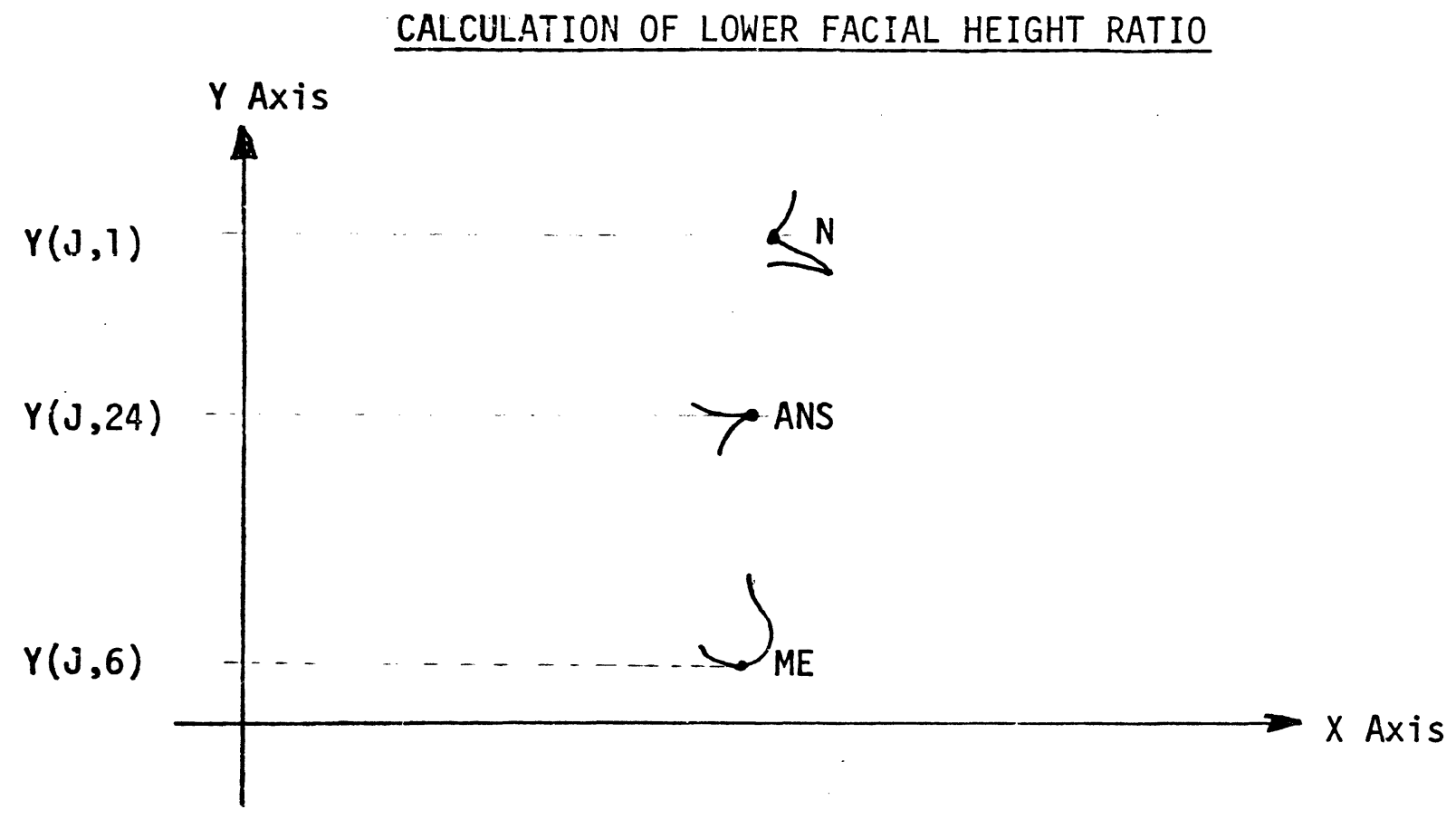

DEFINITIONS

$N(J, 1 \emptyset)$ - Ratio Lower Facial Height ANS-ME/N-ME

Equation

$N(J, 10)=\frac{Y(J, 24)-Y(J, 6)}{Y(J, 1)-Y(J, 6)} * 100$

Note: Ratio is given in $\%$

Fig. 24 


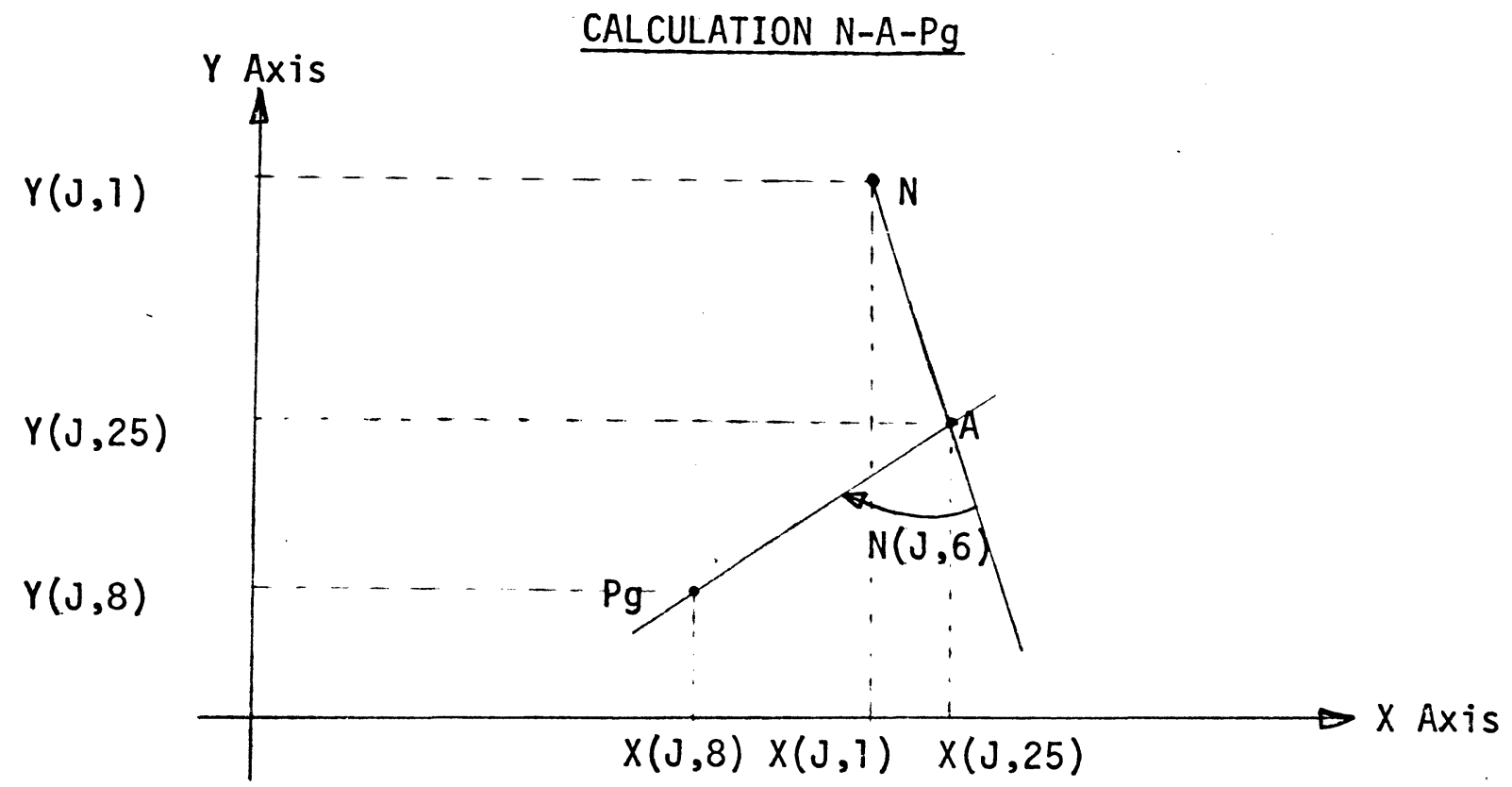

\section{Definitions}

$\mathrm{N}(\mathrm{J}, 6)$ Slope of $\mathrm{N}-\mathrm{A}$ Line and Angle $\mathrm{N}-\mathrm{A}-\mathrm{Pg}$

$N(J, 7)$ Slope of A-Pg Line

$N(J, 15)$ Dummy Used to Check for Divide by Zero

\section{Equations}

$$
\begin{aligned}
& N(J, 6)=\frac{Y(J, 1)-Y(J, 25)}{N(J, 15)} \\
& N(J, 15)=X(J, 1)-X(J, 1)-X(J, 25)
\end{aligned}
$$

Note: If $N(J, 15)=\emptyset$ then $N(J, 15)=0.001$

$$
N(J, 7)=\frac{Y(J, 25)-Y(J, 8)}{X(J, 25)-X(J, 8)}
$$

$N(J, 6)=\operatorname{TAN}^{1}\left(\frac{N(J, 7)-N(J, 6)}{1-\left(N(J, 7)^{\star} N(J, 6)\right)}\right)$ 


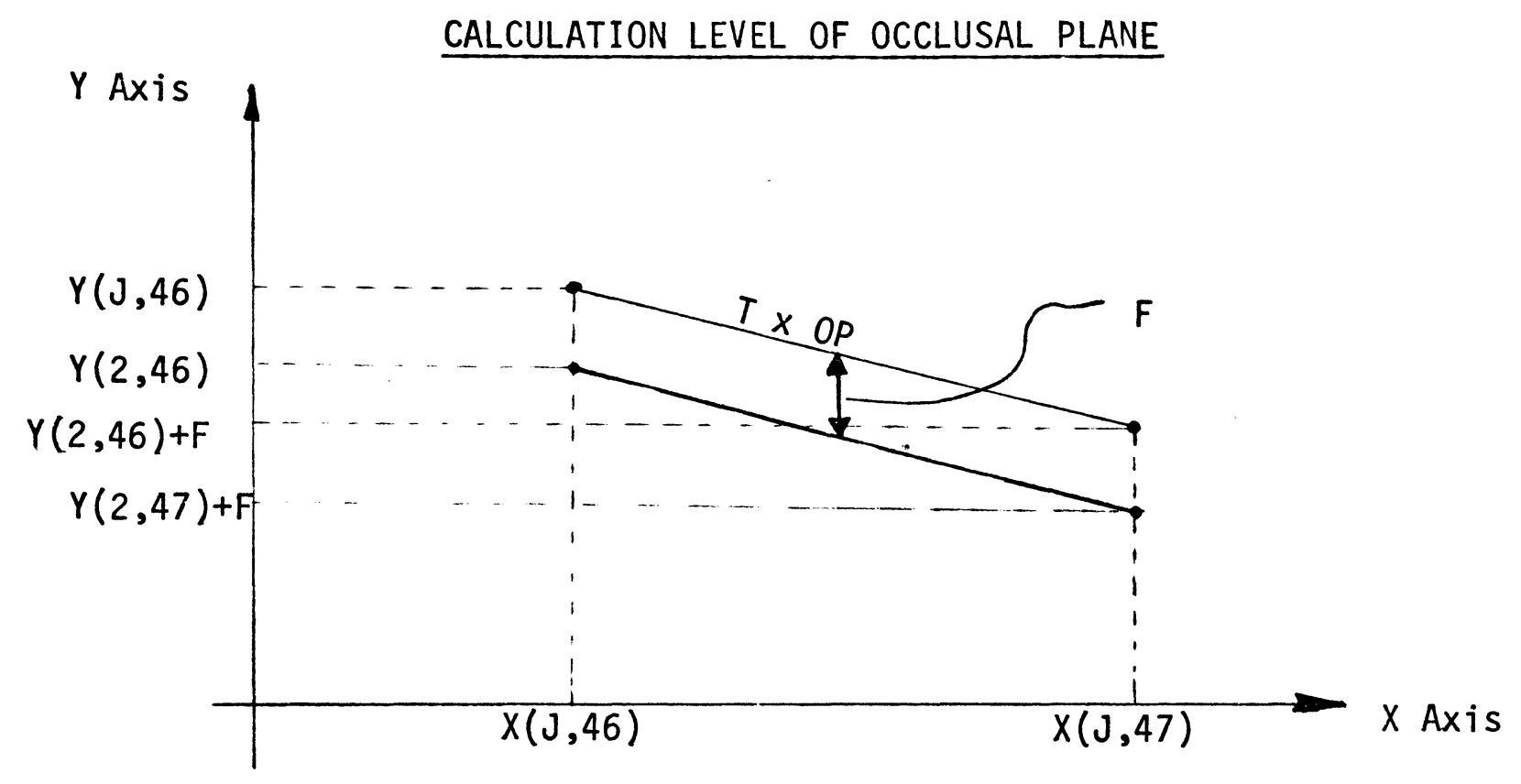

Definition

$F=Y$ Axis increment Change

\section{Equations}

$$
\begin{aligned}
& Y(2,46)=Y(0,46)+F \\
& Y(2,47)=Y(0,47)+F \\
& X(2,46)=X(0,46) \\
& X(2,47)=X(0,47)
\end{aligned}
$$

Fig. 26 


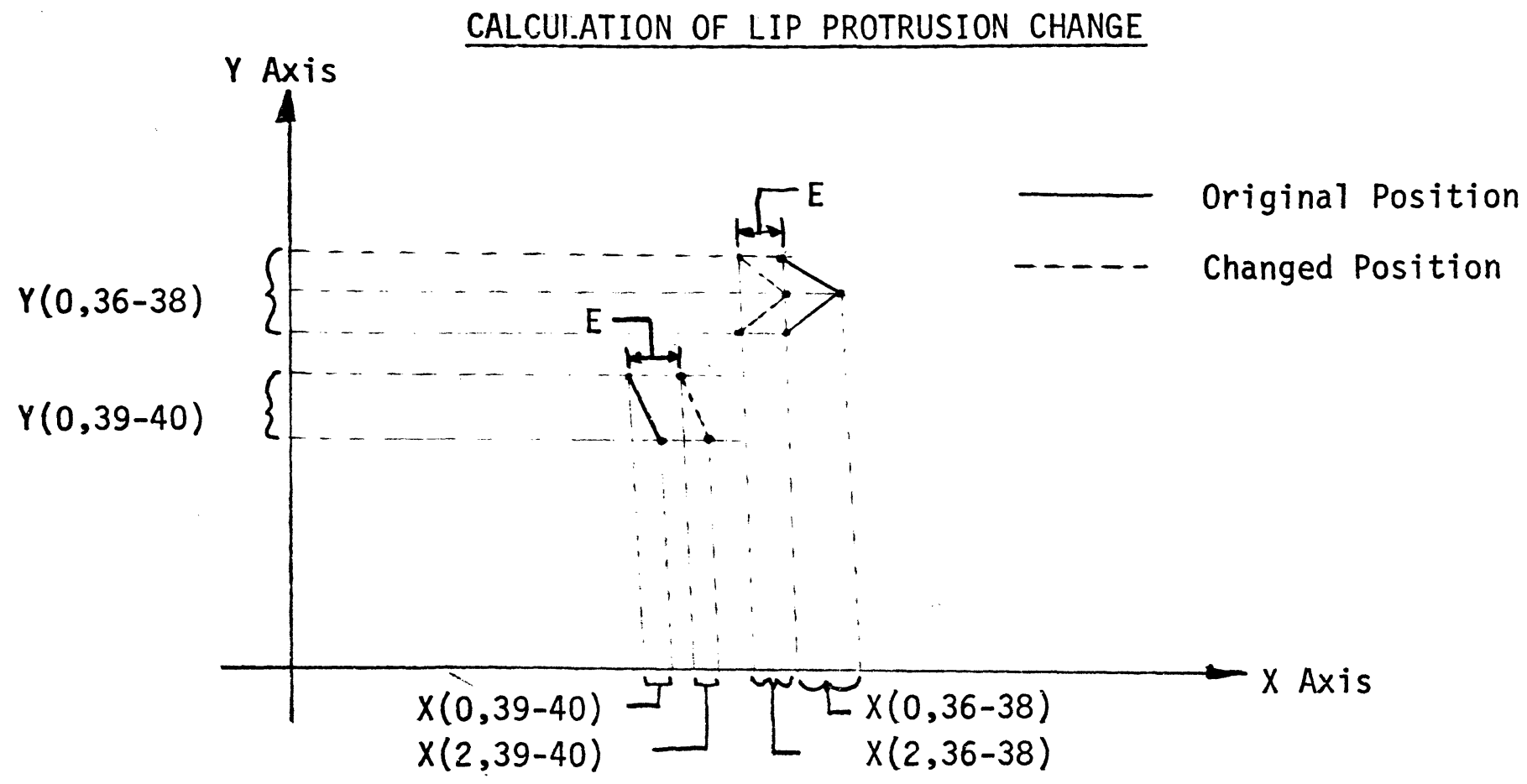

Definition

$E=$ Lip Protrusion Change

Equations

$X(2, I)=X(0, I)+E$

$Y(2, I)=Y(2, I)$

Fìg. 27 


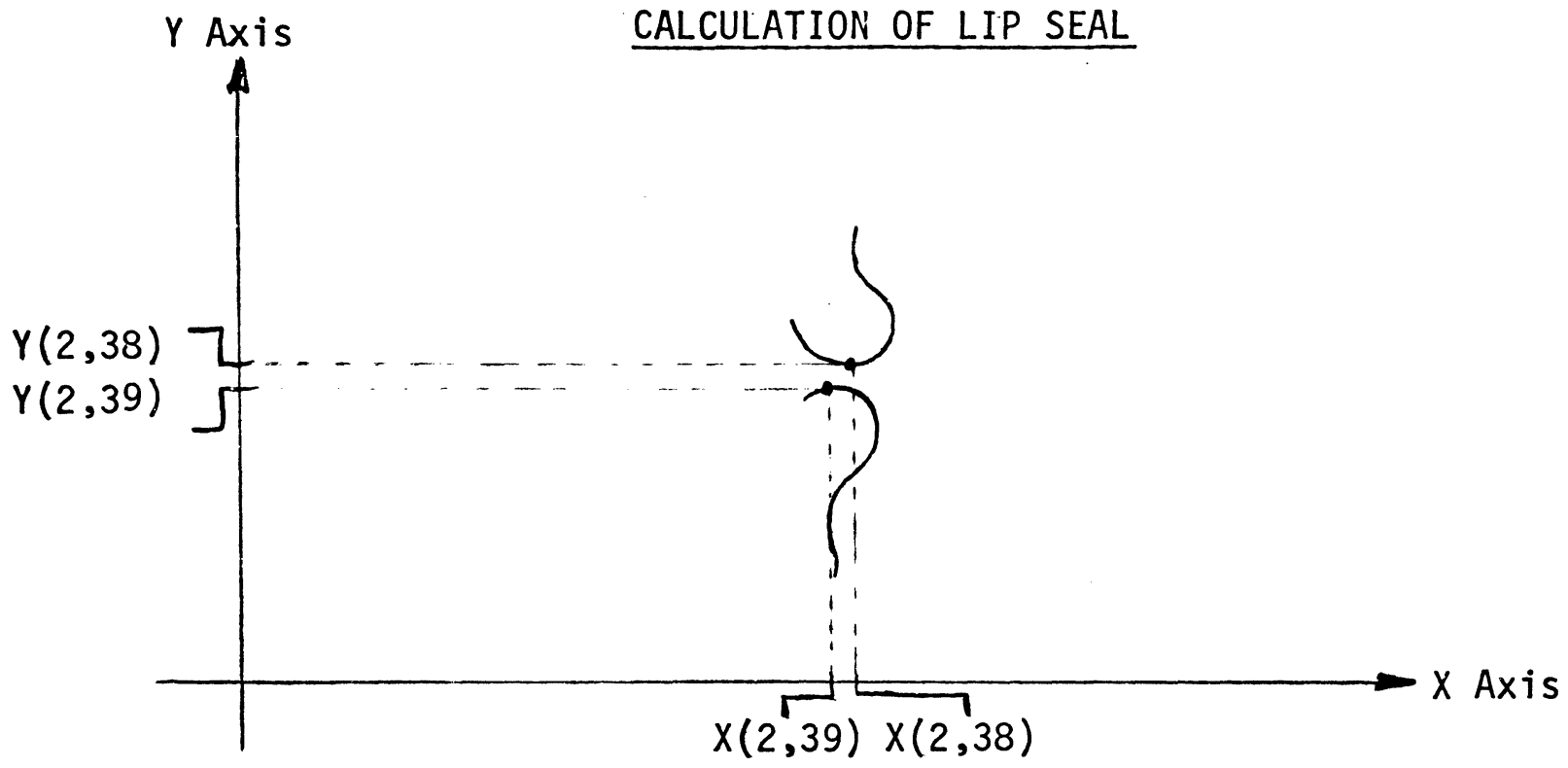

Definitions

C = Calculation Dummy

$X(2,38) ; Y(2,38)=$ Coordinates of Upper Lip

$X(2,39) ; Y(2,39)=$ Coordinates of Lower Lip

\section{Equations}

$$
\begin{aligned}
& \text { Horizontal Seal }=C=\frac{X(2,38)-X(2,39)}{2} \\
& C=X(2,39)+C \\
& X(2,38)=X(2,39)=C \\
& \text { Vertical Seal }=C=\frac{2}{3}(Y(2,38)-Y(2,39)) \\
& C=Y(2,39)+C \\
& Y(2,39)=Y(2,38)=C
\end{aligned}
$$

Fig. 28 


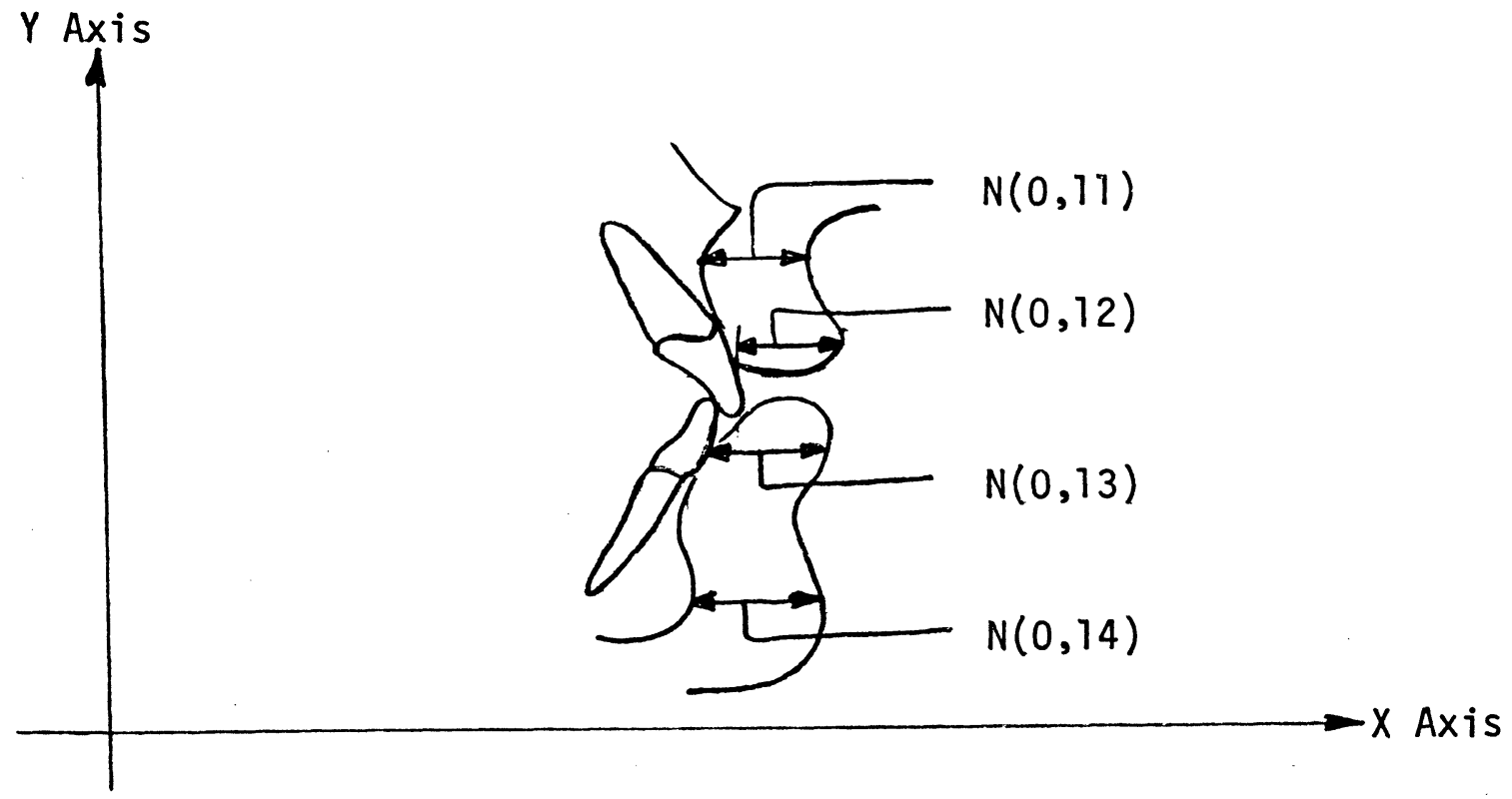

Definitions and Equations

$$
\begin{aligned}
& N(0,11)=\text { Thickness A-Sn }=X(0,35)-X(0,25) \\
& N(0,12)=\text { Thickness U1-UL }=X(0,37)-X(0,26) \\
& N(0,13)=\text { Thickness L1-LL }=X(0,40)-X(0,10) \\
& N(0,14)=\text { Thickness Pg-Pg }=X(0,42)-X(0,8)
\end{aligned}
$$

$T(\emptyset)=$ Difference from $A-S n=N(0,12)-N(0,11)$

$\cdot T(1)=$ Difference from $A-S n=N(0,13)-N(0,11)$

$T(2)=$ Difference from $A-S n=N(0,14)-N(0,11)$

$T(3)=$ Difference from standard $=T(\emptyset)+4$
$T(4)=$ Difference from standard $=T(1)+3$
$T(5)=$ Difference from standard $=T(2)+4$

Note: Measurements are taken parallel to Frankfort Horizontal (X-Axis) this is the reason an update for upper and lower lip thickness may be required. 


\section{CALCULATION OF ESTIMATED LOWER INCISOR POSITION}

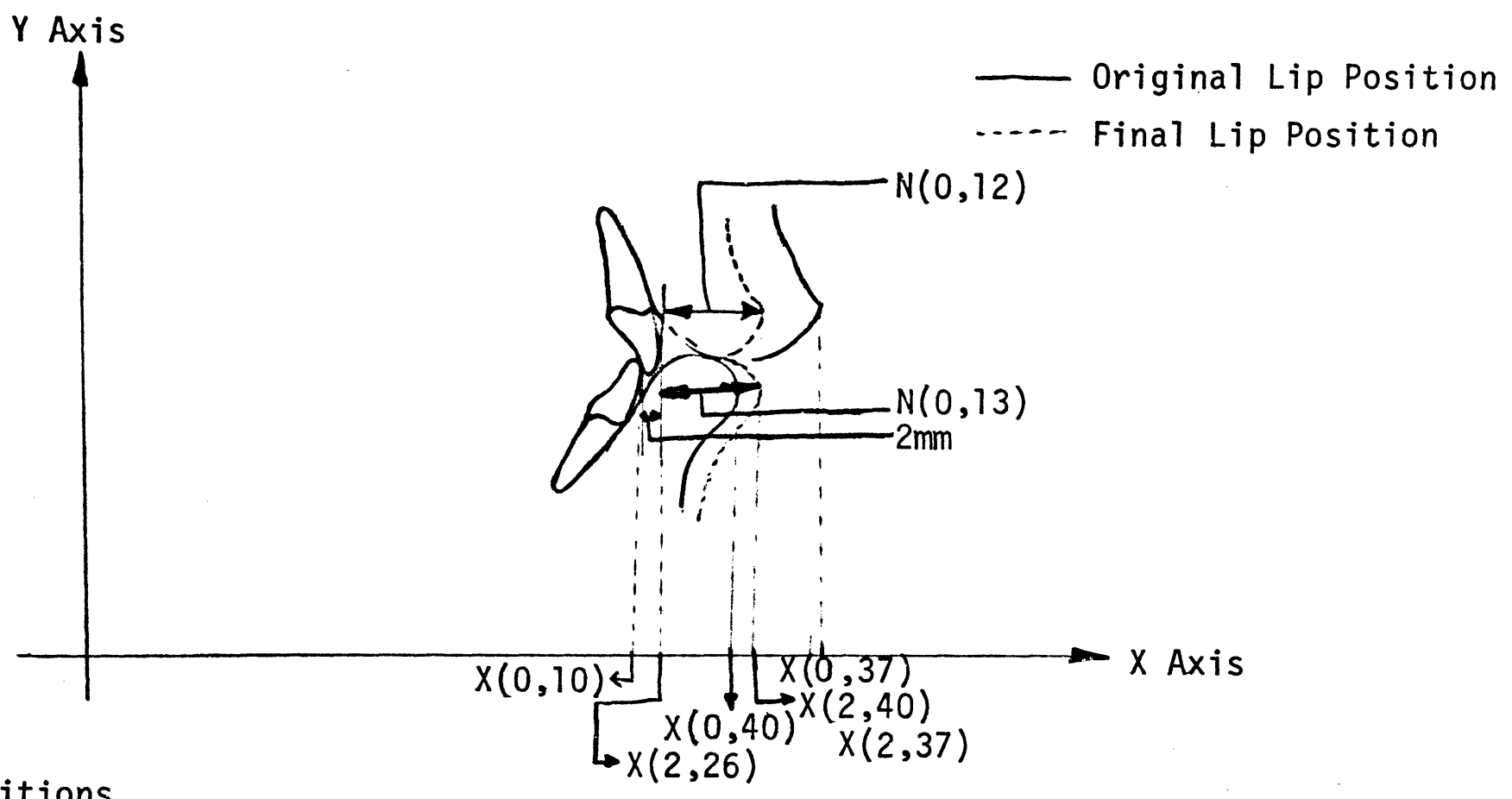

Definitions

$$
\begin{aligned}
& T(6)=\text { Change in Lower Incisor Position } \\
& T(7)=\text { Change in Upper Incisor Position } \\
& E \\
& =\text { Incisor Correction Factor }
\end{aligned}
$$

\section{Equations}

$$
\begin{aligned}
& T(6)=(X(2,40)-N(0,13)-2)-X(0,10)) \\
& T(7)=0.6^{*}(X(2,37)-N(0,12)-X(0,26)) \\
& X(2, I)=X(0, I)+E
\end{aligned}
$$

Note:

For U1 $E=T(7)$

For LI $E=T(6)$ 
TABLE I

LIST OF VARIABLES USED IN TREATMENT PLANNING PROGRAM

VARIABLE

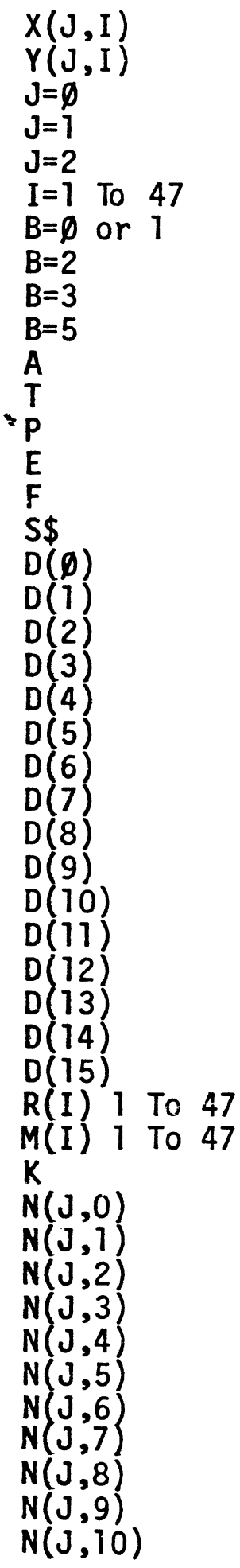

\section{DESCRIPTION}

$X$ Cartesian Coordinates

Y Cartesian Coordinates

Original Data

Growth Updated Data

Rotated or Translated Points

Index Points on Model

Response to Program Inquires

Add Correction to J-2 Point and Draw Draw Update Point as Presented

Dummy to Avoid $B=0,1,2,3$

Used as Time Delay Clock Counter

Scale Factor (set for 75)

Used to Set Print Index

Input for $X$ or Horizontal Changes

Input for $Y$ or Vertical Changes

Used to Input Literals

Degree to Radian Conversion

S-N Growth Increments

Input Growth Increment

PNS-ANS Growth Increment Horizontal

N-ANS Growth Increment Verticai

$Y$ Axis Growth Increment

$Y$ Axis Angle Input

MM Displacement OP

Scale $T / 100$

Center of Rotation X Variable

Center of Rotation $Y$ Variable

Rotation Angle in Radians

Rotation Angle at Start in Radians

$X$ Used in $A-P g$ or $A-B$ Measurement

$Y$ Used in $A-P g$ or $A-B$ Measurement

Intermolar Dimension Vertical

Cistance in Polar Coordinates

Angle in Polar Coordinates

Plot Offset From Lower Border

Calculation Dummy

Negative Reciprocal of OP Slope

$A B(O P)$

Vertical ANS-ME

Interlabial Gap

Vertical Dimension \%

Angle Convexity Calcualtion

Angle Convexity

Rotation OP Variable

Rotation OP

Lower Facial Height Calculation 


$$
-2-\left(C^{\prime}{ }^{\prime} t\right)
$$

\section{TABLE I}

\section{VARIABLE}

$N(J, 11)$

$N(J, 12)$

$\mathrm{N}(\mathrm{J}, 13)$

$N(J, 14)$

$N(J, 15)$

$\mathrm{N}(\mathrm{J}, 16)$

$T(\emptyset)$

$T(1)$

$\mathrm{T}(2)$

$T(3)$

$\mathrm{T}(4)$

$T(5)$

$\mathrm{T}(6)$

$T(7)$

$T(8)$

T(9)

$T(10)$

$\mathrm{T}(11)$

C

G

\section{DESCRIPTION}

Soft Tissue A-SN

Soft Tissue UT-UT

Soft Tissue L]-LL

Soft Tissue PG-PG'

Divide By Zero Check

OP Divide by Zero Check

Soft Tissue Ratio UL

Soft Tissue Ratio LL

Soft Tissue Ratio PG

Soft Tissue Difference UL

Soft Tissue Difference LL

Soft Tissue Difference PG

LI Position

U1 Position

Ideal LI Position

Dummy

Dummy

LL Change

Dummy for Roundoff 0.1

Tab Offset Indicator

NOTE: In Ceph 4 some of variables have been reused to facilate ease in printout coordination. 
TABLE II

LIST OF GOSUBS USED IN TREATMENT PLANNING PROGRAM

GOSUB

9000

8000

9010

6121

8802

5002

4900

5033

6202

6504

1070

1076

1080

5426

8922

6802

6854

6856

6682

8990

6451

5404

5502

5512

5522

5532

5542

5552

5572

5602

5632

5662

5682

5702

5712

5722

5732

5742

6142

6662

8971

8981

6742

6420

1131

6722

7001

7008

5008

5009
PURPOSE

Initialize Graphics

Print Introduction

Erase Screen

Time Delay After Erase

Initialize Variables to Zero

Input Digitized Data

Correction Digitized

Normalize and Scale Data

Initialize Graphics Display

Input Growth Prediction

Draw Original Headplate

Draw Growth Headplate

Draw Rotated \& Translated Headplate

Print Scale

Set Up OP

DB Rotation OP

Set Print

Continue Print Line Count

Rotate Cant OP

Plot Point (Spot Print)

Calculate $A B(O P)$

Plot Headplate

Plot Cranial Base

Plot L6

Plot U6

Plot Upper Face

Plot Lower Face

Plot Mandible

Plot Maxillia

Plot LI

Plot U1

Plot $\mathrm{FH}$

Plot OP

Plot LL

Plot UL

Update Growth Coordinates

Update Growth Coordinates

Update Growth Coordinates

Plot Line Segments

Polar Coordinate XForm

Divide by Zero Check

Round off $(0.1)$

Rotation Mandible DB

Rotate Mandible

Calculate Intermolar Distance

Calculate N-A-PG

Calculate \% Facial Height

DB Level OP

Dimension

Dimension
SECTION (CEPH)

1
1
1
1
1

$1,2,3,4$

$1,2,3,4$

1

$1,2,3,4$

1

$1,2,3$

$1,2,3$

$1,2,3$

$1,2,3$

1

1

$1,2,3,4$

$1,2,3,4$

1

$1,2,3,4$

$1,2,3,4$

$1,2,3$

$1,2,3$

$1,2,3$

$1,2,3$

$1,2,3$

$1,2,3$

$1,2,3$

$1,2,3$

$1,2,3$

$1,2,3$

$1,2,3$

$1,2,3$

$1,2,3$

$1,2,3$

1

1

1

$1,2,3$

$1,2,3$

$1,2,3,4$

$1,2,3,4$

2

2

2,4

$2,3,4$

$2,3,4$

2

$1,2,3,4$

$1,2,3,4$ 
$-2-\left(\operatorname{Con}^{\prime} t\right.$.)

\section{TABLE II}

\section{GOSUB}

5010

8961

7102

7122

7132

7161

7242

6874-6

7402

7372

7310

7280
PURPOSE

Dimension

Divide By Zero Check

AP-L1 Plot

Plot SN-PG

Plot A-PG

DB Profiles

Move UL/LL

Set Print

Update Soft Tissue Thickness

Calculate Lip Seal

Auto Update Li/UT

Move UT/LT

\section{SECTION (CEPH)}

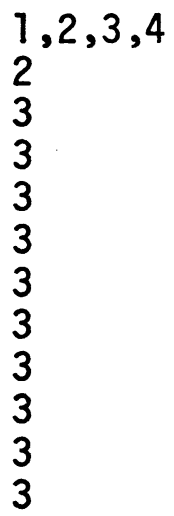




\section{TABLE II I}

\section{LIST OF CALLS USED IN TREATMENT PLANNINGG PROGRAM}

CALL

$\operatorname{CALL}(3, N, Y(J, I))$

$\operatorname{CALL}(4, N, Y(J, I))$

CALL (5)
FUNCTION

Write Data Onto Disk File

Read Data From Disk File

Return to Disk File Manager 


\section{ACKNOWLEDGEMENT}

The author would like to thank Dr. Charles Burstone for guidance and help in pursuing this project to its completion. Also to be thanked is Dr. David Solonche for his technical advice and his effort in ensuring that the hardware was operational throughout the period that this project was undertaken. 